Published in final edited form as:

Toxicol Appl Pharmacol. 2008 April 1; 228(1): 93-104.

\title{
The contribution of c-Jun $\mathrm{N}$-terminal kinase activation and subsequent $\mathrm{Bcl}-2$ phosphorylation to apoptosis induction in human B-cells is dependent on the mode of action of specific stresses
}

\author{
Donna E. Muscarella* and Stephen E. Bloom \\ Department of Microbiology and Immunology, Cornell University, Ithaca, NY 14853, U.S.
}

\begin{abstract}
The c-Jun N-terminal kinase (JNK) pathway can play paradoxical roles as either a pro-survival or a pro-cell death pathway depending on type of stress and cell type. The goal of the present study was to determine the role of JNK pathway signaling for regulating B-cell apoptosis in two important but contrasting situations-global proteotoxic damage, induced by arsenite and hyperthermia, versus specific microtubule inhibition, induced by the anti-cancer drug vincristine, using the EW36 B-cell line. This cell line over-expresses the $\mathrm{Bcl}-2$ protein and is a useful model to identify treatments that can overcome multi-drug resistance in lymphoid cells. Exposure of EW36 B-cells to arsenite or lethal hyperthermia resulted in activation of the JNK pathway and induction of apoptosis. However, pharmacological inhibition of the JNK pathway did not inhibit apoptosis, indicating that JNK pathway activation is not required for apoptosis induction by these treatments. In contrast, vincristine treatment of EW36 B-cells resulted in JNK activation and apoptosis that was suppressed by JNK inhibition. A critical difference between the two types of stress treatments was that only vincristineinduced JNK activation resulted in phosphorylation of Bcl-2 at threonine-56, a modification that can block its anti-apoptotic function. Importantly, Bcl-2 phosphorylation was attenuated by JNK inhibition implicating JNK as the upstream kinase. Furthermore, arsenite and hyperthermia treatments activated a p53/p21 pathway associated with apoptosis induction, whereas vincristine did not activate this pathway. These results reveal two stress-activated pathways, one JNK-dependent and another JNK-independent, either of which can bypass Bcl-2 mediated resistance, resulting in cell death.
\end{abstract}

\section{Keywords}

apoptosis; arsenite; vincristine; Bcl-2; c-Jun N-terminal kinase; B-cell; lymphoma

The differential propensity of various populations of B-lymphocytes to undergo apoptosis is an important factor that regulates normal immune system function as well as the development and subsequent clinical outcomes of lymphoid malignancies. A variety of signaling pathways, including the stress activated protein kinase/c-Jun N-terminal kinase (JNK) pathway, and apoptosis-regulating proteins, such as the Bcl-2 family of mitochondrial proteins, are

*Corresponding author: Dr. Donna Muscarella, Department of Microbiology and Immunology, C4-101 VMC, Cornell University, Ithaca, NY 14853, Fax: 607-253-3384, Tel: 607-253-4047, e-mail: dem10@cornell.edu.

Publisher's Disclaimer: This is a PDF file of an unedited manuscript that has been accepted for publication. As a service to our customers we are providing this early version of the manuscript. The manuscript will undergo copyediting, typesetting, and review of the resulting proof before it is published in its final citable form. Please note that during the production process errors may be discovered which could affect the content, and all legal disclaimers that apply to the journal pertain. 
differentially expressed in lymphoid cells and play a central role in regulating B-cell survival or death (Merino et al., 1994). For example, developing B-lymphocytes express increasing levels of Bcl-2 protein as they progress through various steps of maturation in the germinal center of lymph-nodes. The aberrant over-expression of Bcl-2 is frequently observed in lymphoma and other types of cancers (Manion and Hockenbery, 2003). Elevated Bcl-2 results in resistance to apoptotic cell death induced by chemotherapeutic drugs (Gaidano et al., 1991; Fan et al., 1994). Furthermore, immunotoxic environmental chemicals, as well as many anti-lymphoma drugs, are potent activators of JNK. This pathway plays a pivotal role in the regulation of cell survival and cell death depending on the context of its activation - i.e. the particular cell type and chemical involved (Sakata et al., 1995,1999; Chen et al., 1996; Meriin et al., 1999; Fan et al., 2001). An emerging picture of B-cell biology underscores the complex interaction of these, and other, apoptosis-regulating factors. Thus, predicting the outcome of chemical/drug exposure in lymphoid cells requires the identification of the specific molecular targets of various classes of chemicals and understanding of how the interaction of these targets ultimately determines whether cells survive or undergo apoptosis.

The Bcl-2 family consists of several closely related pro- and anti-apoptotic proteins that play a crucial role in influencing the susceptibility of cells to apoptosis following exposure to chemical stresses and physiological signals. In mitochondria, Bcl-2 proteins occur as homoor hetero-dimers in a multi-protein complex that modulates ion flux and outer membrane potential. The best characterized of the regulatory interactions among Bcl-2 family members is that between $\mathrm{Bcl}-2$ and Bax. Following drug-induced signaling, Bax, and other pro-apoptotic Bcl-related proteins, undergo allosteric changes that lead to the formation of multimers inserted within the mitochondrial outer membrane resulting in channel formation, loss of mitochondrial membrane potential, and release of several apoptogenic proteins including cytochrome $\mathrm{c}$. This latter event marks the irreversible commitment of cells to apoptotic cell death. The antiapoptotic activity of Bcl-2 is attributed, in part, to its ability to interact with and sequester Bax as well as other pro-apoptotic proteins. Thus, the ratio of pro- and anti-apoptotic Bcl-related proteins in cells is an important aspect of apoptosis regulation. The relative levels of pro- and anti-apoptotic Bcl-2 family members are controlled by the transcriptional activation of their respective genes. For example, when activated by DNA damage, the tumor suppressor protein, p53 directs the transcription of apoptosis-promoting members of the family, including Bax and Puma (Yu et al., 2001; Yamaguchi et al., 2004; Wong et al., 2005).

The activity of several Bcl-2 family members is further modulated by specific protein modifications, including phosphorylation (Yamamoto et al., 1999; Fan et al., 2000a, 2000b; Bhalla, 2003). Although several recent studies have shown that the Bcl-2 protein itself is the target for phosphorylation at multiple sites, the signals and conditions in which Bcl-2 is phosphorylated are not completely understood. The precise sites that are phosphorylated in Bcl-2 depend on the cell type, various upstream stimuli, and on cell cycle progression. However, preponderance of the evidence indicates that phosphorylation inhibits the ability of Bcl-2 to interact with and antagonize the activity of pro-apoptotic members. Thus, this Bcl-2 modification is generally considered to be an apoptosis-promoting event.

Importantly, some cases of Bcl-2 phosphorylation occur normally, in the context of regulation of the G2/M transition (checkpoint) in the cell cycle and are believed contribute to the elimination of damaged cells. However, others occur in response to exposure to specific classes of chemicals - in particular those that disrupt microtubule function, such as the anti-cancer drugs vincristine and paclitaxel. Studies reveal that two critical sites of phosphorylation are threonine -56 and serine-70, both of which are located within a flexible loop region of the protein (Srivastava, 1999; Yamamoto et al., 1999). Deletion of the loop or mutation of these specific amino acids, so that phosphorylation cannot occur, enhances apoptosis-resistance in 
cells, further supporting the hypothesis that these Bcl-2 phosphorylations are pro-apoptotic events.

One pathway commonly involved in mediating Bcl-2 phosphorylation is the JNK pathway (Yamamoto et al., 1999; Fan et al., 2000a; 2000b). Depending on the specific cell type and context of activation, JNK may function as either a proliferative / anti-apoptotic (i.e. when activated by growth factors or cytokines) or a pro-apoptotic (i.e. when activated by some cytotoxic chemicals) regulator in cells. Understanding how the JNK pathway influences such varied cellular outcomes, and how this pathway integrates its activity with the important apoptosis-regulating proteins is an important question that remains to be answered.

We have previously described an in vitro model consisting of germinal center-derived human B-lymphocyte cell lines for studying drug-induced apoptosis (O’Brien et al., 2001; Muscarella and Bloom, 2002; Muscarella et al., 2003; Bloom et al., 2006). These B-cell lines retain phenotypic features of germinal center B-lymphocytes including the expression of characteristic surface markers and serve as an important model system to study the critical period in B-cell maturation during which cells undergo either apoptosis (i.e. negative selection) due to the activation of the B-cell receptor alone, or clonal expansion and proliferation (i.e. positive selection), due to the simultaneous activation of the B-cell and CD40 receptors. Importantly, these B-cell lines show differences in p53 and in the expression of Bcl-2 protein that corresponds to their marked differential sensitivity to apoptosis induction by a variety of chemicals as well as physical stresses. One cell line in particular, the EW36 B-cell line expresses wild-type p53 as well as high levels of Bcl-2 and low levels of Bax, and is a useful model to identify factors that may overcome Bcl-2 mediated resistance to apoptosis induction (Muscarella and Bloom, 2002; Muscarella et al., 2003; Bloom et al., 2006)

We previously reported that EW36 B-cells undergo toxicant-induced apoptosis in a manner associated with JNK activation along with the concurrent activation and transcriptional induction of its downstream nuclear target, the transcription factor c-Jun (Muscarella and Bloom, 2002; Muscarella et al., 2003). We also reported a synergistic effect of multiple exposures, such as non-lethal heat stress and low-concentrations of arsenite as well as some mitochondrial toxicants, resulting in substantially elevated levels of apoptosis in EW36 Bcells. This synergistic effect was associated with enhanced/prolonged activation of JNK and induction of c-Jun protein (Muscarella and Bloom, 2002; Bloom et al., 2006). However, pharmacological inhibition of JNK did not inhibit - and under some circumstances enhanced - apoptotic cell death, leading us to conclude that, under these conditions, the JNK pathway is not pro-apoptotic but rather is a stress response that protects against cell death (Bloom et al., 2006).

The main goal of the present study was to determine the role of the JNK-signaling pathway in regulating apoptosis induction in two contrasting stress conditions: global proteotoxic damage versus specific microtubule damage and inhibition. Cell injury involving proteotoxic damage can be induced by exposure to metals including arsenic, which reacts with sulfhydryl groups on proteins, as well as physical treatments such as heat stress, which causes general protein denaturation. In contrast, anti-microtubule agents bind specifically to tubulin and inhibit microtubule functions. Agents such as vincristine are used extensively in the clinical treatment of cancers, including lymphoma, breast cancer, and neuroblastoma. Therefore, our study has relevance to the broad question of how apoptosis is regulated in B-cells in the context of clinical as well as environmental-chemical exposure.

We show that two major types of cell stress, global proteotoxic damage induced by arsenic (as well as heat stress) and microtubule damage induced by vincristine, result in JNK pathway activation and apoptosis induction in B-cells. However, JNK-pathway activation is required 
for apoptosis only in the case of vincristine-induced microtubule inhibition and involves JNKmediated phosphorylation of $\mathrm{Bcl}-2$. In contrast, global proteotoxic stress leads to apoptosis in a JNK-independent manner and is associated with the activation of a p53 pathway.

\section{MATERIALS AND METHODS}

\section{Chemicals and antibodies}

Sodium arsenite, and vincristine were obtained from Sigma Chemical Co. Stocks of sodium arsenite were prepared in water and vincristine in DMSO, both at 1000X. Antibodies specific for Bcl-2 phosphorylated at threonine 56 (cat\# 2875), phosphorylated and total -JNK1/2 (cat\# 9251 and 9252, respectively), phosphorylated (serine 15) and total p53 (cat\# 9284 and 2524, respectively), and p21 (cat\# 2946) were purchased from Cell Signaling Inc. The antibody that recognizes the $113 \mathrm{kD}$ full length poly (ADP ribose) polymerase (PARP) and the $85 \mathrm{kD}$ cleavage product (PARP; AAP-250) and the antibody for Hsp 70 (SPA 812) were purchased from Stressgen, Inc. Antibodies for c-Jun (sc1694) and total Bcl-2 (sc509) were obtained from Santa Cruz. The JNK inhibitor SP600125 (SP6; Anthra[1,9-cd]pyrazol-6(2H)-one-1,9pyrazoloanthron), JNK inhibitor II (a structural but inactive analogue of SP6 serving as a negative control; N1-methyl-1,9, pyrazoloanthrone), JNK inhibitor V, (a structurally unrelated JNK inhibitor, 1,3,-benzothiazole-2-yl-(2-(2-(3-pyridinyl)ethyl)amino)-4-pyrimidinyl acetonitrile), the ERK inhibitor U0126, and p38 inhibitor SB202190 (SB2), were obtained from Calbiochem Inc. All inhibitors were dissolved in DMSO. We previously performed experiments to optimize conditions of exposure of EW36 cells to SP6, U0126, and SB2 (Muscarella and Bloom, 2002; Muscarella et al., 2003; Bloom et al., 2006) and found our conditions consistent with those reported in the literature. Thus, concentrations of inhibitors in their range of $10-20 \mu \mathrm{M}$ were necessary to block the activities of the respective kinases in the absence of measurable, non-specific, effects on other kinases. Additional experiments with the JNK inhibitor V were performed (data not shown) in which a working concentration of 10 $\mu \mathrm{M}$ was found to be adequate to inhibit JNK-activity, as measured by induction of c-Jun protein without increasing baseline levels of apoptosis/necrosis in the cells.

\section{Cell lines and experimental culture conditions}

The EW36 B-cell line was obtained from Dr. Ian T. Magrath, National Cancer Inst., Bethesda, MD and was cultured in medium RPMI 1640, (GIBCO) supplemented with $15 \%$ fetal calf serum, penicillin-streptomycin and L-glutamine. Cells were grown at $37^{\circ} \mathrm{C}, 5 \% \mathrm{CO}_{2}$ and $95 \%$ humidity. The cell line is Epstein Barr virus-negative. For all experiments, cultures were set up at a density of $0.3 \times 10^{6}$ cells $/ \mathrm{ml}$ and allowed to grow for $24 \mathrm{~h}$. Cells were plated into 6well plates, $4 \mathrm{ml}$ each, and $4 \mu \mathrm{l}$ of $1000 \mathrm{X}$ stocks of either arsenite or vincristine was added. For experiments involving inhibition of JNK, SP6 was added to cultures for a period of $1 \mathrm{~h}$ prior to drug addition and/or heat treatment. For experiments involving heat stress, cells were transferred to $15 \mathrm{ml}$ culture tubes and incubated in a water bath at $43^{\circ} \mathrm{C}$ for $45 \mathrm{~min}$ (non-lethal heat stress, NL HS) or 60 min (lethal heat stress, L HS). Cells were then plated into 6-well plates and then incubated for an additional $4 \mathrm{~h}$ before drug addition. At the designated times, $800 \mu 1$ of cells were harvested for protein immunoblotting as previously described below (Muscarella and Bloom, 2002)

\section{Cellular and molecular detection and quantitation of apoptosis}

The induction of apoptosis and necrosis was carefully diagnosed by a well-validated double fluorescence method (Muscarella and Bloom, 1997; Lieberthal et al., 1998). This procedure allows for rapid, direct diagnosis of apoptotic cell phenotypes by observing condensed, segregated chromatin masses fluorescing blue. Necrotic cells are also easily detected in the same cell samples by observation of red fluorescence in cells due to propidium iodide uptake across damaged cell membranes. Briefly, $250 \mu \mathrm{l}$ of cell suspension was stained in $20 \mu \mathrm{g} / \mathrm{ml}$ 
propidium iodide (emitting red fluorescence) and $100 \mu \mathrm{g} / \mathrm{ml}$ Hoechst 33342 (emitting blue fluorescence) for $15 \mathrm{~min}$, at $37^{\circ} \mathrm{C}$ in the dark. The double fluorescence was detected with a Leitz Aristoplan microscope equipped with an epifluorescence system and a long-pass filter cube A. Digital images of fluorescently labeled cells were obtained using a Spectra-Imager 5000 cooled color microscopy image and analysis system with AlphaEase imaging software (Alpha Innotech, San Leandro, CA). Dead cells emit red and live cells blue fluorescence. Apoptotic cells have a characteristic phenotype of condensed, segregated chromatin bodies in intact but shrunken cells. The apoptotic phenotype was easy to detect and discriminate from necrotic cells, which were swollen, had irregular/damaged membranes and fluoresced red from propidium iodide that entered these damaged cells. Also, the chromatin in such cells was minimally condensed with some accumulation near the nuclear membrane. Typically, 200 cells were scored for each sample and classified as either necrotic, apoptotic, or normal/viable.

The induction of apoptosis in the EW36 B-cell lines was confirmed and further characterized by a biochemical assay. In the apoptotic pathway of B-lymphoid and many other cell lines, activated caspase- 3 cleaves the protein PARP in response to chemical treatments. In the PARP apoptosis assay, the ratio of cleaved, $85 \mathrm{kD}$, PARP fragment to the full-length, $115 \mathrm{kD}$, protein as determined by densitometry of protein immounoblots (described below) provides a measure of the extent of apoptosis in the cell population (Muscarella and Bloom, 2002).

\section{Protein Immunoblotting}

The extent of PARP cleavage and activation of the JNK pathway, Bcl-2 phosphorylation, and activation of $\mathrm{p} 53 / \mathrm{p} 21$ by the heat stress and chemical treatments, was evaluated by protein immunoblotting as described (Muscarella and Bloom, 2002) using antibodies indicated in above. Briefly, following heat stress and chemical exposure, cells were washed in phosphate buffered saline (PBS) and solubilized in $1 \times$ Laemmli sample buffer (65.2 $\mathrm{m} M$ Tris-Cl, pH 6.8, $25 \%$ glycerol, $2 \%$ SDS, $0.01 \%$ bromphenol blue, and $5 \% \beta$-mercaptoethanol). $20 \mu \mathrm{g}$ of protein or $2 \times 10^{6}$ cells/sample was subjected to SDS-PAGE in a 4 to $15 \%$ gradient gel. Gels were electrophoretically transferred to nitrocellulose membrane (Bio-Rad) in $25 \mathrm{~m} M$ Tris, pH 8.3, $192 \mathrm{mM}$ glycine, $20 \% \mathrm{MeOH}$. For detection of phosphorylated kinases, membranes were first probed with antibodies specific for the phosphorylated forms of JNK1/2 and c-Jun. Filters were subsequently re-probed using antibodies that recognize the proteins independent of phosphorylation status to serve as loading controls and insure that differences in signal were due to phosphorylation of the protein and not to differences in amounts of total protein. Membranes were washed in TBS (20 $\mathrm{m} M$ Tris, $500 \mathrm{mM} \mathrm{NaCl}$, pH 7.5) then blocked for $1 \mathrm{~h}$ in TBS containing 5\% dried milk. Filters were then washed in TBS containing $0.1 \%$ Tween-20 then incubated overnight at $4{ }^{\circ} \mathrm{C}$ with primary antibody diluted appropriately in TBS containing $5 \%$ bovine serum albumin. Filters were washed again, and incubated with the second antibody - horseradish peroxidase-conjugate. Detection was then performed using an enhanced chemiluminescent (ECL) system. Quantitation of the signals on films was performed using an Alpha Imager 3400 Documentation and Analysis System, equipped with AlphaEase version 3.2.1 software (Alpha Innotech, San Leandro, CA).

\section{Statistical analysis of the data}

In apoptosis experiments, 200 cells were analyzed for each treatment, and all experiments were replicated. Statistical evaluations of all data sets were performed using the statistical program NCSS 6.0 (Kaysville, UT). Percentage data were transformed by arc sine, prior to statistical analysis, to normalize the data. The data were analyzed by ANOVA. If the F-statistic was significant, post-hoc comparisons among control and treatment groups were made using Fisher's least significant difference test. For Western blots, quantitation of the signals will be performed using an Alpha Imager IS-3400 Documentation and Analysis System, equipped with AlphaEaseFC software (Alpha Innotech Corp.). Quantitative data from this analysis were 
subjected to ANOVA and treatment differences were determined either by pair wise t-test or Tukey's Studentized range test. The level of statistical significance for all analyses was set at $\mathrm{p}<0.05$.

\section{RESULTS}

\section{JNK-mediated phosphorylation of Bcl-2 mediates apoptosis induction following microtubule damage induced by vincristine but not from global protein damaged induced by arsenite}

Activation of the JNK pathway is associated with apoptosis induction by a variety of agents and is often considered a pro-apoptotic pathway. This pathway has the capability of phosphorylating multiple cellular targets, including nuclear substrates such as the transcription factor c-Jun, and cytoplasmic substrates such as Bcl-2. To what extent these different targets of JNK are activated by various apoptosis-inducing treatments, and their ultimate role in cell death, has not been well established.

We compared two important chemicals, sodium arsenite and vincristine, which differ with respect to their molecular targets in cells, and examined their effects on JNK activation, phosphorylation/induction of downstream JNK-targets Bcl-2 and c-Jun, respectively, and apoptosis induction in EW36 B-cells. Arsenite is a proteotoxic chemical that reacts with sulfhydryl groups in proteins and can induce the formation of reactive oxygen species. In contrast, vincristine specifically binds tubulin subunits thereby disrupting microtubule dynamics. Proliferating cells are thus blocked at metaphase (M-phase arrest) through this mechanism. The EW36 B-cell line over-expresses the Bcl-2 protein and is therefore relatively resistant to apoptosis induction by many agents. However, they are capable of undergoing apoptosis concurrent with the activation of the JNK pathway (Muscarella and Bloom 2002; Muscarella et al., 2003; Bloom et al., 2006).

Both vincristine and arsenite activated the JNK pathway in EW36 cells (Figure 1) as measured by the dose-dependent increase in phosphorylation of JNK (p-JNK) and by the subsequent induction of expression of its downstream target gene, c-Jun, as measured by increased levels of the c-Jun protein. Levels of total JNK protein (JNK) were similar for all treatments thus showing equal loading of proteins for each lane. Importantly, only arsenite induced Hsp 70 protein, consistent with its mode of action. Sulfhydryl damage by arsenite causes the unfolding of proteins and global accumulation of such damaged proteins is a primary inducer of Hsp 70 and of other stress proteins. In contrast, exposure to vincristine did not result in Hsp 70 induction. Furthermore, we confirmed that, consistent with its role in blocking microtubule function, vincristine exposure led to the accumulation of mitotically-arrested cells determined by flow cytometry and by the accumulation of blocked metaphase cells detected by fluorescence microscopy (data not shown).

The time-dependent kinetics of JNK phosphorylation was also similar between arsenite and vincristine, with both agents showing a sustained activation of the pathway (Figure 1B). The appearance of phosophorylated JNK, along with elevated levels of c-Jun protein, was detected shortly after drug addition (by $2 \mathrm{~h}$ ). The induction of c-Jun protein was somewhat delayed in vincristine- compared to arsenite-treated cultures (reaching maximal levels at 8 and $24 \mathrm{~h}$, respectively). At the $24 \mathrm{~h}$ time point, levels of phospho-JNK started to decline concomitant with an increase in the levels of cleaved PARP - a caspase 3 substrate whose cleavage is indicative of activation of the apoptotic pathway.

The induction of apoptosis by arsenite and vincristine was also measured by direct microscopic examination of fluorescently stained cells that allows for the simultaneous detection and quantification of apoptotic as well as necrotic cells (see Materials and Methods). Furthermore, to elucidate the potential role of the JNK pathway in apoptosis induction, we treated cultures 
in parallel with the JNK inhibitor SP600125 (SP6; Bennett et al., 2001). SP6 is a specific and potent catalytic inhibitor of JNK that has been widely employed to determine the contribution of the JNK pathway to apoptosis induced by numerous agents in a variety of cell types. It has been particularly useful in elucidating the role of the JNK pathway in the induction of apoptosis in primary cell cultures and established cell lines of B-lymphoid lineage cells (Bloom et al., 2006; Schlezinger et al., 2006).

Both arsenite and vincristine induced apoptosis in EW36 B-cells in a concentration dependent manner (Figure 2; A and B, respectively). No necrotic cells were detected. Importantly, SP6 attenuated apoptosis significantly in vincristine- but not in arsenite-treated cultures. This suggested that, despite the activation of JNK by both agents, this pathway appears to be dispensable for apoptosis induced by arsenite but not by vincristine. We confirmed these results by blotting for PARP and found that SP6 suppressed vincrisitne-, but not arsenite-, induced PARP cleavage (Figure 3A; PARP, -SP6 compared to +SP6). Importantly, SP6 did bock the induction of c-Jun protein by both agents (Figure 3A, c-Jun, -SP6 compared to +SP6). Since c-Jun is an important downstream target of JNK, inhibition of c-Jun induction indicated that the inhibitor is blocking the JNK pathway equally for both agents.

Together, these data suggested a differential role of JNK following activation by arsenite compared to vincristine. Thus, we sought to identify a potential downstream target of JNK that would account for the differential effect of SP6 on suppression of apoptosis. Among the recently identified downstream targets of JNK that contribute significantly to apoptotic response in cells is Bcl-2. Phosphorylation of this protein is known to block its anti-apoptotic activity. Since the EW36 B-ell line strongly over-expresses Bcl-2, we examined its phosphorylation following drug treatment. Importantly, we found that only vincristine, not arsenite, resulted in a robust phosphorylation of Bcl-2 at thr 56 (Figure 3B) that was first detected at $2 \mathrm{~h}$. Moreover, the induction of phospho-Bcl-2 by vincristine paralleled that of cJun induction (Figure 3A) with respect to drug concentration. Furthermore, c-Jun expression and Bcl-2 phosphorylation were both blocked by treatment with SP6, strongly invoking JNK as the upstream kinase.

To further support the role of JNK in vincristine-mediated phosphorylation of Bcl-2 we examined the effects of several other commercially available inhibitors, including a second, structurally different, JNK-inhibitor (JNK inhibitor V; Gaillard et al., 2005), and an inactive structural analogue of SP6 (JNK inhibitor II; Bennett et al., 2001) that served a negative control for SP6. Although SP6 is the most commonly used inhibitor of the pathway, both it and JNK inhibitor V are ATP-competitive inhibitors that show a high degree of specificity towards the JNK1, 2, and 3 isoforms compared to a variety of other kinases (Bennet et al., 2001, Gaillard et al., 2005). In addition, we also examined the effect of inhibitors of the ERK and p38 pathways (U0126 and SB2, respectively). We previously reported that these MAP kinase pathways were activated following arsenite exposure in EW36 cells and established conditions for their respective inhibitors in order to determined the potential roles of these pathways in B-cell apoptosis (Muscarella and Bloom, 2002; Muscarella et al., 2003; Bloom et al., 2006).

Only JNK inhibitor V inhibited vincristine-induced PARP cleavage, as well as c-Jun protein induction (Figure 4A). JNK inhibitor II (the negative control), had no effect on PARP and cJun. Furthermore, the ERK and p38 kinase inhibitors, U0126 and SB2, did not affect vincristine-induced PARP cleavage or c-Jun induction. Accordingly, we found no evidence for activation of ERK and p38 MAP kinase pathways by vincristine, nor did the inhibitors affect vincristine-induced apoptosis or Bcl-2 phosphorylation (data not shown).

A more detailed analysis of JNK inhibitor V confirmed that, like SP6, this inhibitor blocked vincristine-induced phosphorylation of Bcl-2 (Figure 4B). Furthermore, vincristine-induced 
apoptosis, as scored by the cytological fluorescence assay, was significantly reduced by JNK inhibitor V (Figure 5). In contrast, arsenite-induced apoptosis was not affected (data not shown). Thus, we conclude that the JNK pathway is required for vincristine, but not arseniteinduced apoptosis in EW36 B-cells with JNK-mediated phosphorylation of Bcl-2 being a critical regulatory event.

\section{Non-lethal, but not lethal, heat stress can attenuate vincristine-induced apoptosis in a JNK/ phospho-Bcl-2 dependent pathway}

Similar to arsenite, heat treatment is a proteotoxic stress that activates the JNK pathway and induces apoptosis. In addition to being an environmentally relevant stress, hyperthermia is used clinically to treat some types of cancer. Heat stress also serves as an important experimental model to induce cellular damage characterized by global denaturation of proteins, the magnitude of which can be modulated by treatment length and temperature.

We have previously shown that arsenite and lethal heat stress synergize to induce apoptosis in EW36 cells (Muscarella and Bloom 2002; Bloom et al., 2006). However, heat stress also activates cytoprotective pathways in cells mediated by the induction of several heat stress proteins that act as molecular chaperones stabilizing proteins against damage and facilitating the refolding of denatured proteins. In this context, non-lethal heat stress has been shown to be protective against apoptosis induction by some agents (Lee et al., 1992; Samali and Cotter, 1996).

We compared the effect of limited, non-lethal heat stress $\left(43^{\circ} \mathrm{C}\right.$ for $30 \mathrm{~min}$, NL HS) and more prolonged, lethal heat stress $\left(43^{\circ} \mathrm{C}\right.$ for $\left.60 \mathrm{~min}, \mathrm{~L} \mathrm{HS}\right)$ on vincristine-induced apoptosis in EW36 B-cells). Both treatments induced heat stress proteins, including Hsp70 (Figure 6A) and Hsp90 (data not shown) in a manner that is unaffected by concurrent vincristine exposure. Importantly, the outcomes of the two different heat-stress scenarios differed significantly.

Non-lethal heat stress attenuated the magnitude of vincristine-induced JNK phosphorylation (p-JNK) as well as Bcl-2 phosphorylation (P-Bcl-2) (Figure 6B). In addition, the level of vincristine-induced PARP cleavage (Figure 6B, PARP) as well as apoptosis scored cytologically (Figure 7) was significantly reduced in cultures treated with non-lethal heat stress prior to vincristine addition. In contrast, lethal heat-stress treatment on its own induced JNK phosphorylation (Figure 8A; +L HS, $0 \mu \mathrm{M}$ vincristine). The combination of lethal heat stress plus the highest concentration of vincristine $(0.1 \mu \mathrm{M})$ resulted in JNK phosphorylation that was slightly less than additive. Moreover, the amount of apoptosis induced by the combination of lethal-heat stress plus vincristine (Figure 8B), paralleled the level of JNK-phosphorylation. (No necrotic cells were detected using either non-lethal or lethal heat stress.) Additionally, we found that SP6 did not block apoptosis induced by lethal heat stress or by the combination of lethal heat stress plus vincrisitne (data not shown).

Together these data suggest that vincristine induces apoptosis by a JNK/phospho-Bcl-2 dependent pathway that can be attenuated by treatment with pharmacological inhibition of JNK or attenuation of the JNK pathway by non-lethal heat stress, both of which block Bcl-2 phosphorylation. In contrast, treatments that induce gobal proteotoxic damage, arsenite and lethal heat stress, induce apoptosis in a JNK- independent manner thus invoking a role for other pro-apoptotic pathways.

\section{Role of the p53 pathway in heat stress- and arsenite -induced apoptosis}

We sought to identify possible pathways outside of JNK that are involved in apoptosis induction. Specifically, we examined the p53 pathway (Figure 9). Although the p53 tumor suppressor gene is often mutated in cancer cells, resulting in resistance to drug-induced 
apoptosis, the EW36 B-cell line has wild-type p53. Thus, this pathway presents a possible target that may override the protective effects of Bcl-2 over-expression subsequently inducing apoptosis in the EW36 B-cells.

We found that lethal heat stress robustly activated the p53 pathway indicated by the increased phosphorylation of p53 (phospho-p53) and an increase in total p53 due to stabilization of the protein. Furthermore, a concurrent increase in $\mathrm{p} 21$ protein, encoded by a downstream $\mathrm{p} 53$ target gene, was observed (Figure 9A; +L HS). In contrast, non-lethal heat stress showed only a minimal activation of the p53 pathway (Figure 9A; +NL HS). Similarly, arsenite treatment robustly activated the p53/p21 pathway, particularly at higher concentrations that correspond to levels required to induce apoptosis (Figure 9B)

\section{DISCUSSION}

Several models have been proposed to explain the paradoxical role of the JNK pathway as a pro-survival/proliferative or a pro-death pathway. For example, cross-talk between JNK and other cellular pathways, such as nuclear factor kappa-B, may determine the repertoire of target genes that are induced and the subsequent cellular outcomes (Lee et al., 1997; Mecurio et al., 1999). In addition, the duration of JNK activation has been proposed to be an important modulating factor. Transient activation of the pathway, occurring after stimulation by growth factors, has been associated with cell proliferation whereas sustained activation, occurring after exposure to chemical/physical stresses, is associated with cell death (Chen et al., 1996; Gabai et al., 2000; Muscarella and Bloom, 2002; Wicovsky et al., 2007). However, these observations do not fully explain the complex role of JNK in stress-induced apoptosis. In the present study we show that even when activated by potent, apoptosis-inducing treatments, the requirement for JNK in B-cell apoptosis induction is agent-specific, and depends on its downstream targets, which include either nuclear or cytoplasmic substrates.

Two classes of stress inducing treatments were used in our study: global proteotoxic stress induced by arsenite or lethal heat treatment compared to specific inhibition of microtubule function induced by vincristine. Both activated the JNK pathway in a sustained manner, as analyzed by phosphorylation of the JNK protein and induction of its downstream target c-Jun protein. However, two structurally unrelated JNK inhibitors, SP6 and JNK inhibitor V (Bennet et al., 2001, Gaillard et al., 2005) blocked apoptosis induced only by vincristine, not by arsenite. In contrast, an inactive structural analogue of SP6 had no effect, nor did inhibitors of ERK and p38 MAP kinase pathways commonly activated by cellular stress. A major difference found among the treatments was that only vincristine induced the phosphorylation of Bcl-2.

Importantly, vincristine-induced apoptosis and Bcl-2 phosphorylation were both blocked by inhibitors of JNK (SP6 and JNK V). Although we cannot formally exclude the potential involvement of some other kinases, the fact that two unrelated JNK inhibitors yielded similar results strongly implicate JNK as an important Bcl-2 - phosphorylating kinase. Furthermore, our results showing that phosphorylation of $\mathrm{Bcl}-2$ is a proapoptotic event is consistent with other published studies (Yamamoto et al., 1999; Fan et al., 2000a, 2000b).

Several sites in the Bcl-2 protein, including threonine 56 , are typically phosphorylated at the G2/M transition (checkpoint) of the cell cycle. It is believed that G2/M-associated Bcl-2 phosphorylation serves to promote the elimination of aberrant cells by sensitizing them to the induction of apoptosis during this critical phase in the cell cycle. The JNK pathway appears to be responsible for this cell-cycle-related phosphorylation of Bcl-2. Therefore, it has been proposed that drug-induced microtubule damage and the G2/M cell cycle checkpoint overlap with respect to activation the JNK pathway, leading to Bcl-2 phosphorylation and that the cell cycle arrest caused by microtubule inhibitors may provide the key cellular signal. 
We observed a rapid induction of signaling following vincristine exposure. Bcl-2 phosphorylation occurred concurrently with phosphorylation of JNK and induction of its downstream target, c-Jun, reaching maximal levels within $2 \mathrm{~h}$ of drug exposure. Thus, this rapid phosphorylation of $\mathrm{Bcl}-2$ following the induction of microtubule damage precedes cell cycle arrest or accumulation of G2/M cells which occurs gradually over several hours after addition of the microtubule inhibitor (data not shown). This finding is consistent with the hypothesis that signals induced by microtubule damage directly activate pathways that are also involved in the G2/M checkpoint during typical cell cycle progression.

An important issue is why arsenite and heat stress do not induce Bcl-2 phosphorylation despite their potent activation if JNK and ability to induce c-Jun. In order to phosphorylate/induce nuclear targets such as c-Jun, JNK must translocate to the nucleus. This event requires the association of the kinase with the scaffolding protein, JNK-interacting protein (JIP). Genetic disruption of JIP blocks the nuclear translocation of JNK and subsequent induction of c-Jun, but its ability to phosphorylate Bcl-2 is unaffected (Fan et al., 2000b). Thus, there is at least one major bifurcation point in the JNK pathway that distinguishes its nuclear from cytoplasmic targets (Figure 10) and that may be differentially activated by various agents. The events that lead the differential targeting of downstream JNK-substrates by various chemical stresses are presently unknown although they may be related to the fact that these treatments differentially activate additional signaling pathways outside of JNK. For example, there is evidence that activation of JNK following microtubule damage involves upstream signaling by ASK1 and Ras (Wang et al., 1998) whereas arsenite exposure results in the activation of several MAP kinase pathways in addition to JNK.

Importantly, our data indicate that global protein damage alone may not be the critical signal initiating JNK-pathway activation by arsenite. Hsp70 induction, a known response to general protein damage, was induced at low concentrations of arsenite and by non-lethal heat stress treatments that did not induce JNK phosphorylation or apoptosis. However, arsenite and lethal heat stress have the ability to directly affect mitochondrial function and also increase the generation of reactive oxygen species - events that strongly induce JNK/c-Jun. In addition, although classically induced by DNA-strand breaks, the $\mathrm{p} 53$ pathway has also been shown to be activated by stresses such as arsenite and heat stress most likely by a mechanism involving oxidative damage (Seo et al., 1999; Yih and Lee, 2000; Miyakoda et al., 2002).

The $\mathrm{p} 53$ protein is expressed constitutively at low levels under normal conditions due to its short half-life. Wild-type p53 binds to MDM2, which facilitates its ubiquitinization and subsequent proteosomal degradation. Phosphorylation of 553 protein blocks its binding to MDM2, thus preventing its degradation. This stabilized p53 protein directs the transcription of several apoptosis-associated genes, including those encoding several pro-apoptotic members of the Bcl-2 family. Alternatively, a direct interaction of $\mathrm{p} 53$ with Bcl-2 has recently been reported (Marchenko et al., 2000; Mihara et al., 2003; Deng et al., 2006). These studies showed that $\mathrm{p} 53$ protein is able to bind to $\mathrm{Bcl}-2$ via the flexible loop region thereby inactivating the protein and promoting the release of cytochrome $\mathrm{c}$ from mitochondria. Although we have yet to determine the precise mechanism, our results showing the robust activation of the p53 pathway following treatment with arsenite or lethal heat stress suggest that the activation of the $\mathrm{p} 53$ pathway may overcome Bcl-2 mediated resistance in EW36 B-cells in a manner that is independent of the inactivation of Bcl-2 by phosphorylation.

In the current study, we found that the interaction between heat stress and vincristine and subsequent apoptosis induction depended on the specific conditions of heat exposure. Pretreatment of EW36 B-cells with either limited or prolonged heat stress blocked vincristineinduced Bcl-2 phosphorylation and induced Hsp70. However, pre-treatment of cells with 
limited, non-lethal, heat stress, attenuated vincristine-induced JNK and Bcl-2 phosphorylation and inhibited apoptosis.

Studies have shown that pre-treatment with limited heat stress protects cells against apoptosis induced by subsequent, more extensive, heat stress as well as by certain classes of drugs (Lee et al., 1992; Mosser et al., 1997; Samali and Cotter, 1996). There are several possible mechanisms by which non-lethal heat stress may protect cells against drug-induced apoptosis. As molecular chaperones, heat-stress proteins function to interact with and stabilize proteins, thus protecting them from damage and promoting their re-folding after deaturation. Several apoptosis-regulating proteins have been identified that may be preferentially targeted by Hsp70. For example, Hsp70 has been reported to interact with and block the activity of caspases, thus protecting cells against apoptosis (Mosser et al., 1997, 2000). Alternatively, Hsp70 has also been shown to interact directly with microtubules. Expression of Hsp70 protects 9L rat brain cells from vincristine-induced apoptosis (Lee et al., 1992). At present we do not know the critical targets by which non-lethal heat stress protects EW36 B-cells, although the reduction of $\mathrm{Bcl}-2$ phosphorylation suggests that protection occurs at a point relatively early in vincristine-induced signaling. Although Hsp70 induction and/or inhibition of Bcl-2 phosphoryaltion may be required for this protection, these signals alone are not sufficient lethal heat stress induced apoptosis even in the presence of high levels of the stress protein and inhibition of Bcl-2 phosphorylation. Thus, the activation of other cell death pathways, such as p53, may override the effects of these cytoprotective events.

The findings from our study, summarized in Figure 10, contribute to an understanding of the agent-specific outcomes of JNK activation - a pathway that plays a central role in stresssignaling. In addition, we have identified two mechanisms, one JNK-dependent and the other JNK-independent, facilitating bypass of resistance conferred by Bcl-2 over-expression: first, by JNK-dependent Bcl-2 phosphorylation (following microtubule damage) and, second, by JNK-independent p53 activation (following general protein damage induced by lethal heat stress or arsenite exposure). This study also identified important interactions between the two classes of apoptosis-inducing treatments. The interaction of heat stress with vincristine depended on the specific conditions of heat treatment, with short versus prolonged treatment having essentially opposing effects on cell survival following vincristine treatment. This is significant because the use of heat stress, alone or in conjunction with chemotherapeutic drugs, is currently being explored for the treatment of malignancies (Ohnishi and Ohnishi, 2001). Furthermore, like EW36, lymphomas and other cancers over-express Bcl-2 but retain wildtype $\mathrm{p} 53$. Thus, it has been proposed that targeting the p53 pathway with newer therapies may be an important treatment strategy (Martins et al., 2006). Clearly, the precise conditions of p53 activation and its interaction with other pathways activated by different classes of drugs will profoundly influence the efficacy of this approach and requires detailed molecular information on the modes of action of each agent.

\section{ACKNOWLEDGEMENTS}

We thank Linda Hovanec for technical assistance. The work was supported by grants from the National Institute of Environmental Health Science (R01 ES010815 to D.E.M.) and the Johns Hopkins Center for Alternatives to Animal Testing (CAAT:2005-05 to D.E.M. and S.E.B.)

\section{REFERENCES}

Bennett BL, Sasaki DT, Murray BW, O’Leary EC, Sakata ST, Xu W, Leisten JC, Motiwala A, Pierce S, Satoh Y, Bhagwat SS, Manning AM, Anderson DW. SP600125, an anthrapyrazolone inhibitor of JunN-terminal kinase. Proc. Natl.Acad. Sci. (USA) 2001;98:13681-13686. [PubMed: 11717429]

Bhalla KN. Microtubule-targeted anticancer agents and apoptosis. Oncogene 2003;22:9075-9086. [PubMed: 14663486] 
Bloom SE, Lemley AT, Muscarella DE. Potentiation of apoptosis by heat stress plus pesticide exposure in stress resistant human B-lymphoma cells and its attenuation through interaction with follicular dendritic cells: role for c-Jun N-terminal kinase signaling. Toxicol. Sci 2006;89:214-223. [PubMed: 16237197]

Chen Y-R, Wang X, Templeton D, Davis RJ, Tan T-H. The role of c-Jun N-terminal kinase (JNK) in apoptosis induced by ultraviolet $\mathrm{C}$ and gamma radiation. J. Biol.Chem 1996;271:31929-31936. [PubMed: 8943238]

Deng X, Gao F, Flagg T, Anderson J, May WS. Bcl2's flexible loop domain regulates p53 binding and survival. Mol Cell Biol 2006;26:4421-4434. [PubMed: 16738310]

Fan S, El-Deiry WS, Bae I, Freeman J, Jondle D, Bhatia K, Fornance AJ Jr, Magrath I, Kohn KW, O'Connor PM. p53 gene mutations are associated with decreased sensitivity of human lymphoma cells to DNA damaging agents. Cancer Res 1994;54:5824-5830. [PubMed: 7954409]

Fan M, Goodwin ME, Birrer MJ, Chambers TC. The c-Jun $\mathrm{NH}_{2}$-terminal protein kinase/AP1 pathway is required for efficient apoptosis induced by vinblastine. Cancer Res 2001;61:4450-4458. [PubMed: 11389075]

Fan M, Goodwin M, Vu T, Brantley-Finley C, Gaarde WA, Chambers TC. Vinblastine-induced phosphorylation of Bcl-2 and Bcl-XL in mediated by JNK and occurs In parallel with inactivation of the Raf-1/MEK/ERK cascade. J. Biol. Chem 2000a;275:29980-29985. [PubMed: 10913135]

Fan M, Du L, Stone AA, Gilbert KM, Chambers TC. Modulation of mitogen-activated protein kinases and phosphorylation of Bcl-2 by vinblastine represent persistent forms of normal fluctuations at the $\mathrm{G}_{2}$-M. Cancer Res 2000b;60:6403-6407. [PubMed: 11103805]

Gabai V, Yaglom JA, Volloch V, Meriin AB, Force T, Koutroumanis M, Massie B, Mosser D, Sherman MY. Hsp72-mediated suppression of c-Jun N-terminal kinase is implicated in development of tolerance to caspase-independent cell death. Mol. Cell Biol 2000;20:6826-6836. [PubMed: 10958679]

Gaidano G, Ballerini P, Gong JZ, Inghirami G, Neri A, Newcomb EW, Magrath IT, Knowles DM, DallaFavera R. p53 mutations in human lymphoid malignancies: association with Burkitt lymphoma and chronic lymphocytic leukemia. Proc. Natl. Acad. Sci. (USA) 1991;88:54113-5417.

Gaillard P, Jeanclaude-Etter I, Ardissone V, Arkinstall S, Cambet Y, Camps M, Chabert C, Chursh D, Cirrillo R, Gretener D, Gretener D, Halazy S, Nichols A, Sszyndralewiez C, Vitte P-A, Gotteland J$P$. Design and synthesis of the first generation of novel potent, selective, and in vivo active (benzothiazol-2-yl) acetonitrile inhibitors of the c-Jun N-Terminal kinase. J. Med. Chem 2005;48:4596-4607. [PubMed: 15999997]

Lee FS, Hager J, Chen ZJ, Maniatis T. Activation of the IkBa kinase compex by MEKK1, a kinase of the JNK pathway. Cell 1997;88:213-222. [PubMed: 9008162]

Lee WC, Lin KY, Chen KD, Lai YK. Induction of HSP70 is associated with vincristine resistance in heat-shocked 9L rat brain tumor cells. Br. J. Cancer 1992;66:653-659. [PubMed: 1419602]

Lieberthal W, Menza SA, Levine JS. Graded ATP depletion can cause necrosis or apoptosis of cultured mouse proximal tubular cells. Am. J. Physiol. (London) 1998;274:315-327.

Marchenko ND, Zaika A, Moll UM. Death signal-induced localization of p53 protein to mitochondria. A potential role in apoptotic signaling. J Biol Chem 2000;275:16202-16212. [PubMed: 10821866]

Manion MK, Hockenbery DM. Targeting Bcl-2-related proteins in cancer therapy. Models of Anti-Cancer Therapy 2003;2:S105-S114.

Martins CP, Brown-Swigart L, Evan GI. Modeling the therapeutic efficacy of p53 restoration in tumors. Cell 2006;127:1323-1334. [PubMed: 17182091]

Mecurio F, Manning AM. Multiple signals converging on NF-kB. Current Opinion in Cell Biol 1999;11:226-232. [PubMed: 10209157]

Meriin AB, Yaglom JA, Gabai VL, Mosser DD, Zon L, Sherman MY. Protein-damaging stresses activate c-Jun N-terminal kinase via inhibition of its dephosphorylation: a novel pathway controlled by Hsp72. Mol. Cell Biol 1999;19:2547-2555. [PubMed: 10082520]

Merino R, Ding L, Veis DJ, Korsmeyer SJ, Nunez G. Developmental regulation of the Bcl-2 protein and susceptibility to cell death in B lymphocytes. EMBO J 1994;13:683-691. [PubMed: 8313913]

Mihara M, Erster S, Zaika A, Petrenko O, Chittenden T, Pancoska P, Moll UM. p53 has a direct apoptogenic role at the mitochondria. Mol. Cell 2003;11:577-590. [PubMed: 12667443] 
Miyakoda, Mm; Suzuki, K.; Kodama, S.; Wantanabe, M. Activation of ATM and phosphorylation of p53 by heat shock. Oncogene 2002;21:1090-1096. [PubMed: 11850826]

Mosser DD, Caron AW, Bourget L, Denis-Larose C, Massie B. Role of the human heat shock protein Hsp70 in protection against stress-induced apoptosis. Mol. Cell Biol 1997;17:5317-5327. [PubMed: 9271409]

Mosser DD, Caron AW, Bourget L, Meriin AB, Sherman MY, Morimoto R, Massie B. The chaperone function of hsp70 is required for protection against stress-induced apoptosis. Mol. Cell Biol 2000;20:7146-7159. [PubMed: 10982831]

Muscarella DE, Bloom SE. Differential activation of the c-Jun N-terminal kinase pathway in arseniteinduced apoptosis and sensitization of chemically resistant compared to susceptible B-lymphoma cell lines. Tox. Sci 2002;68:82-92.

Muscarella DE, Bloom SE. Involvement of Gene Specific DNA Damage and Apoptosis in the Differential Toxicity of Mitomycin C Analogs Towards B-Lineage versus T-Lineage Lymphoma Cells. Biochemical Pharmacol 1997;53:811-822.

Muscarella DE, Bloom SE. Cross-linking of surface IgM in the Burkitt's lymphoma cell line ST486 provides protection against arsenite- and stress- induced apoptosis that is mediated by ERK and PI3K signaling pathways. J. Biol. Chem 2003;278:4358-4367. [PubMed: 12464623]

Muscarella DE, O'Brien KA, Lemley AT, Bloom SE. Reversal of Bcl-2 mediated resistance of the EW36 human B-cell lymphoma cell line to arsenite and pesticide-induced apoptosis by PK11195, a ligand of the mitochondrial benzodiazepine receptor. Toxicological Sciences 2003;74:66-73. [PubMed: 12730627]

O'Brien KA, Muscarella DE, Bloom SE. Differential induction of apoptosis and MAP-kinase signaling by mitochondrial toxicants in drug-sensitive compared to drug-resistant B-lineage lymphoid cell lines. Tox. Appl. Pharm 2001;174:245-256.

Ohnishi K, Ohnishi T. Heat-induced p53-dependent signal transduction and its role in hyperthermic cancer therapy. Int. J. Hypertherthermia 2001;17:415-427.

Sakata N, Patel HR, Aruffo A, Johnson GL, Gelfand EW. Selective activation of c-Jun kinase mitogenactivated protein kinase by CD40 on human B cells. J. Biol. Chem 1995;270:30823-30828. [PubMed: 8530526]

Sakata N, Kawasome H, Terada N, Gerwins P, Johnson GL, Gelfand EW. Differential activation and regulation of mitogen-activated protein kinases through the antigen receptor and CD40 in human B cells. Eur. J. Immunol 1999;29:2999-3008. [PubMed: 10508274]

Samali A, Cotter TG. Heat shock proteins increase resistance to apoptosis. Exp Cell Res 1996;223:163170. [PubMed: 8635489]

Schlezinger JJ, Emberley JK, Serr DH. Activation of multiple mitogen-activated protein kinases in pro/ pre-B cells by GW7845, a peroxisome proliferator-activated receptor gamma agonist, and their contribution to GW7845-induced apoptosis. Toxicol. Sci 2006;92:433-444. [PubMed: 16672323]

Seo YR, Smith ML, Han SS, Fairbairn DW, O’Neill KL, Ryu JC. Mild hyperthermia-induced apoptosis is dependent on 553 in human lymphoid cells. Res. Commun Mol. Pathol. Pharmacol 1999;104:285292. [PubMed: 10741379]

Srivastava RK, Mi Q-S, Hardwick MH, Longo DL. Deletion of the loop region of Bcl-2 completely blocks paclitaxel-induced apoptosis. Proc. Natl. Acad. Sci.(USA) 1999;96:3775-3780. [PubMed: 10097113]

Wang T-H, Wang H-S, Ichijo H, Giannakakou P, Foster JS, Fojo T, Wimalasena J. Microtubuleinterfering agents activate c-Jun N-terminal kinase/stress activated protein kinase through both Ras and apoptosis signal-regulating kinase pathways. J. Biol. Chem 1998;273:4928-4936. [PubMed: 9478937]

Wicovsky A, Muller N, Daryab N, Marienfeld R, Kneitz C, Kavuri S, Leverkus M, Baumann B, Wajant H. Sustained JNK activation in response to tumor necrosis factor is mediated by caspases in a celltype specific manner. J. Biol. Chem 2007;282:2174-2183. [PubMed: 17121845]

Wong HK, Fricker M, Wyttenbach A, Villunger A, Michalak WM, Strasser A, Tolkovsky AM. Mutually exclusive subsets of BH3-only proteins are activated by the p53 and c-Jun N-terminal kinse/c-Jun signaling pathways during cortical neuron apoptosis induced by arsenite. Mol. Cell Biol 2005;25:8732-8747. [PubMed: 16166651] 
Yamaguchi H, Chen J, Bhalla K, Wang H-G. Regulation of Bax activation and apoptotic response to microtubule-damaging agents by p53 transcription-dependent and -independent pathways. J. Biol. Chem 2004;279:39431-39437. [PubMed: 15262986]

Yamamoto K, Hidenori I, Korsmeyer SJ. BCL-2 is phosphorylated and inactivated by an ASK/Jun-Nterminal protein kinase pathway normally activated at $\mathrm{G}_{2} / \mathrm{M}$. Mol. Cell Biol 1999;19:8469-8478. [PubMed: 10567572]

Yih LH, Lee TC. Arsenite induces p53 accumulation through ATM-dependent pathway in human fibroblasts. Cancer Res 2000;60:6346-6352. [PubMed: 11103796]

Yu Y, Zhang L, Hwang PM, Kinzler KW, Vogelstein B. PUMA induces the rapid apoptosis of colorectal cancer cells. Mol. Cell 2001;7:673-682. [PubMed: 11463391] 
A

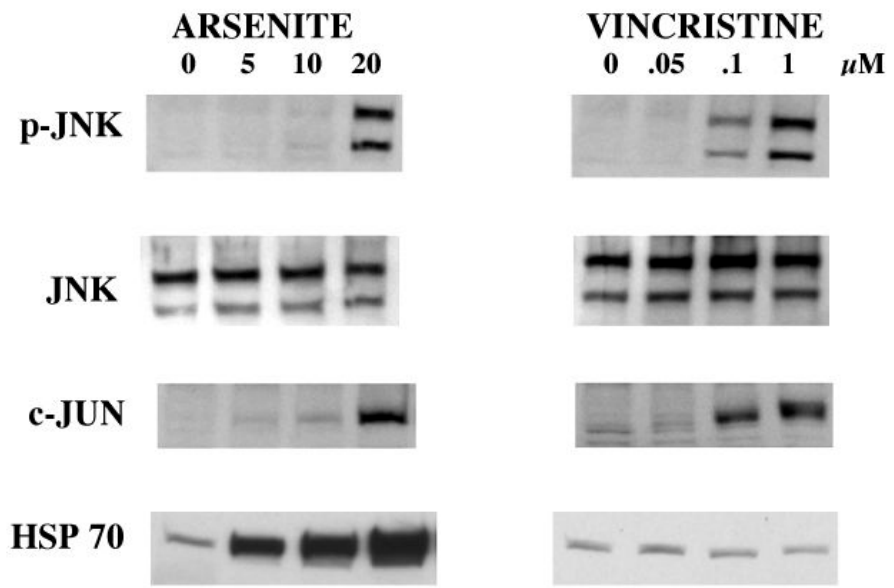

B

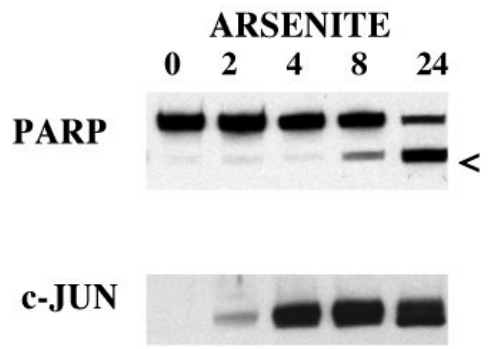

VINCRISTINE $\begin{array}{llllll}0 & 2 & 4 & 8 & 24 & h r\end{array}$ $=0$ p-JNK
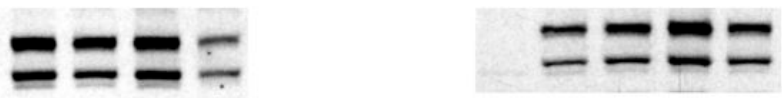

JNK
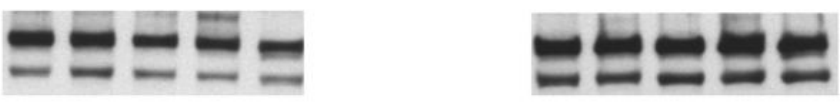

FIG 1.

Differential activation of JNK and HSP 70-stress pathways in EW36 B-cells by arsenite compared to vincristine. (A) Protein lysates were collected from cultures exposed to arsenite or vincristine at the indicated concentrations and subjected to immunoblotting as described in Materials and Methods. The two isoforms of phosphorylated JNK (p-JNK) and total JNK protein (JNK; confirming equivalent loading of protein for each sample) were detected at $2 \mathrm{~h}$ following drug addition. Induction of c-Jun protein (c-JUN) and HSP 70 were determined at $24 \mathrm{~h}$ following drug addition. (B) Time course of JNK-pathway activation and PARP cleavage in arsenite and vincristine-treated EW36 cells. Cultures were exposed to $5 \mu \mathrm{M}$ arsenite or 0.1 $\mu \mathrm{M}$ vincristine and protein lysates collected at the indicated times $(0 \mathrm{~h}$, before addition of drug 
up to $24 \mathrm{~h}$ post-drug addition). Immunoblots were performed to detect cleavage of PARP (arrow), induction of c-Jun protein and phosphorylated JNK (p-JNK). Total JNK (JNK) confirms equivalent loading of protein for each lane. 
A

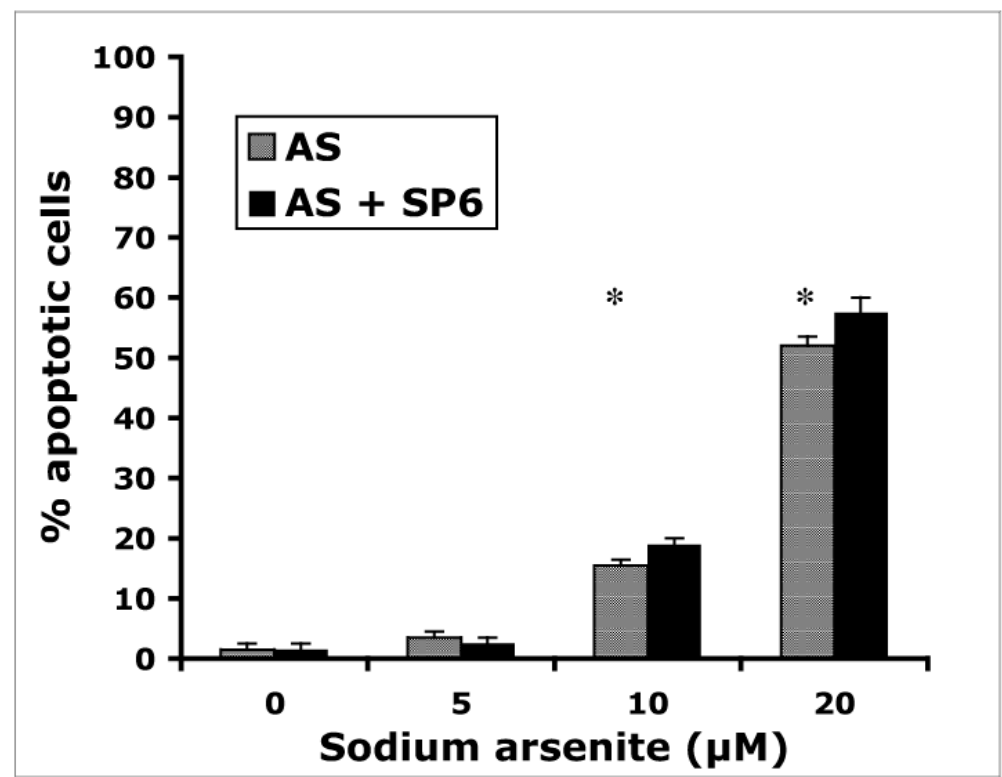

B

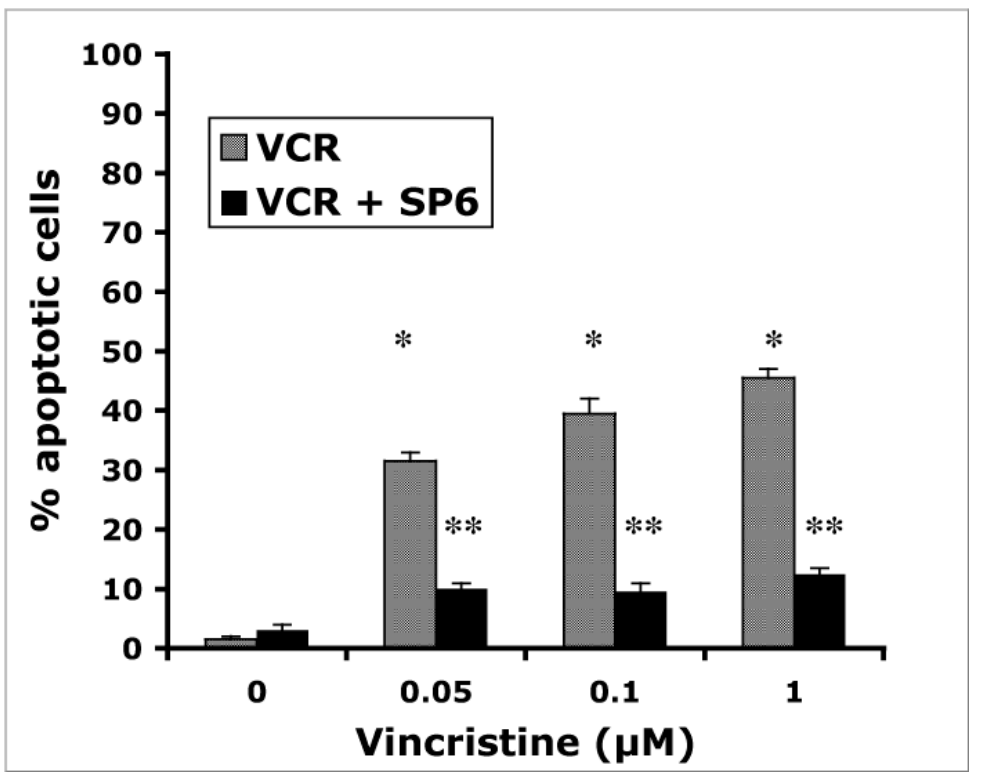

FIG 2.

Suppression of vincristine, but not arsenite-induced apoptosis by pre-treatment with the JNK inhibitor SP6. Cultures of EW36 cells were pre-treated with DMSO control or $20 \mu \mathrm{M} \mathrm{SP6} \mathrm{for}$ $2 \mathrm{~h}$ prior to the addition of either arsenite (A) or vincristine (B) at the indicated concentrations. Percent of apoptotic cells was determined by staining with Hoechst 33342 and propidium iodide (H/PI) followed by diagnosis of apoptosis by fluorescence microscopy as described in Materials and Methods at $24 \mathrm{~h}$. Shaded bars correspond to cultures with chemical alone, solid bars correspond to cultures treated with SP6 prior to chemical addition. Data points are from three experiments with replicate cultures and 200 cells scored per sample. A significant induction of apoptosis over control was seen in cultures exposed to arsenite at 10 and $20 \mu \mathrm{M}$ 
and vincristine at all three concentrations $(* ; p<0.05))$. Apoptosis was significantly suppressed by SP6 pre-treatment for vincristine $(* * ; p<0.05)$ but not for arsenite. 


\section{A}

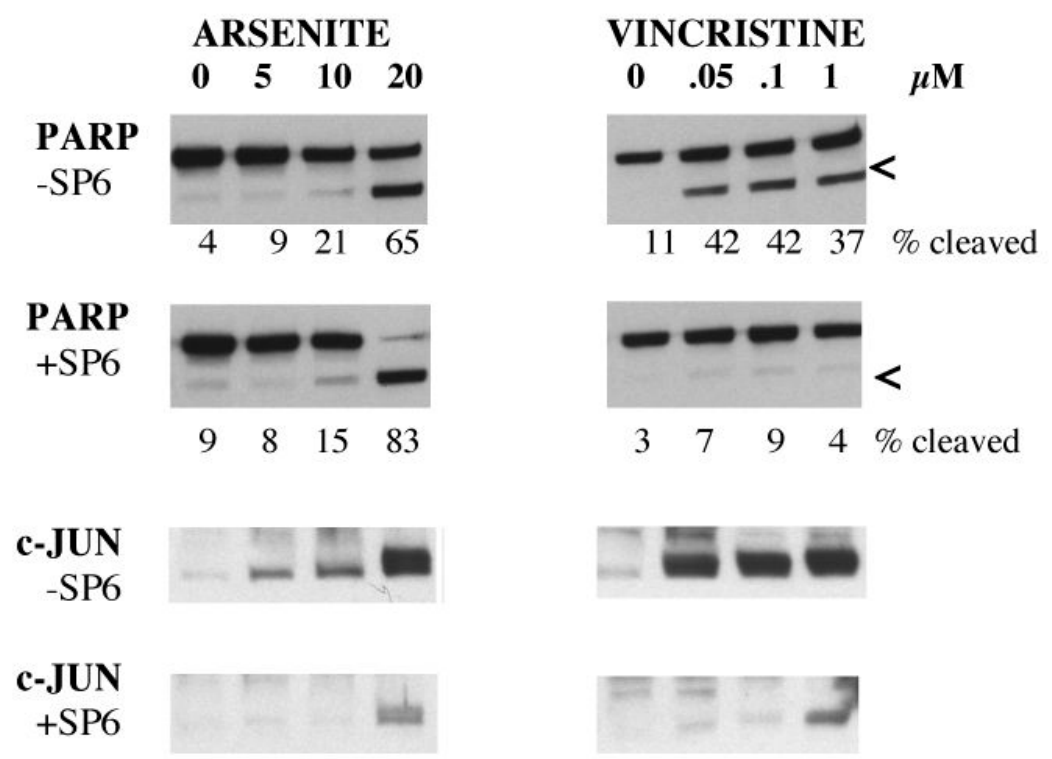

B

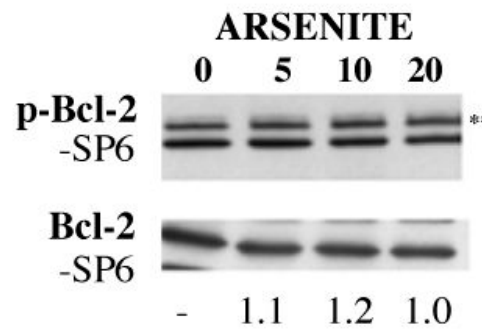

\section{VINCRISTINE}
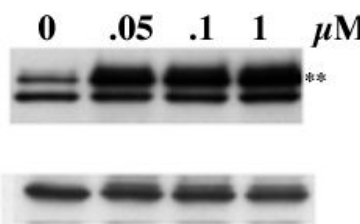

- 2.32 .42 .5 fold
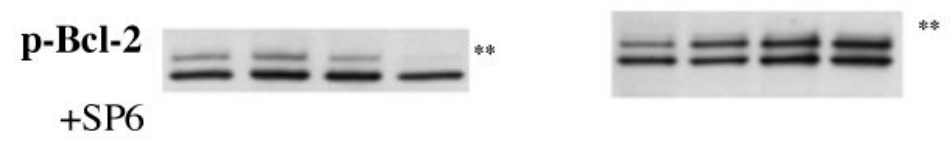

Bcl-2
+ SP6
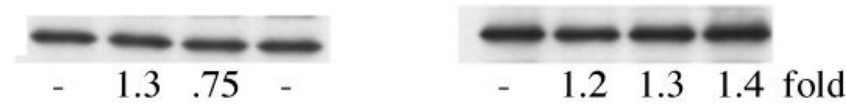

FIG 3.

JNK-mediated phosphorylation of Bcl-2 is required for apoptosis induced by vincristine but not by arsenite. (A) Immunoblots of protein lysates collected following exposure of EW36 Bcells to arsenite or vincristine in the presence or absence of JNK inhibitor SP6 (+SP6 and -SP6, respectively) showing PARP cleavage (arrow) at $24 \mathrm{~h}$ and induction of c-Jun protein at $4 \mathrm{~h}$ following chemical addition. Percent of cleaved PARP as determined by densitometry is indicated below each lane. (B) Differential phosphorylation of Bcl-2 at thr-56. Cultures were treated with SP6 (+SP6) or DMSO control (-SP6) $2 \mathrm{~h}$ prior to the addition of drug. Protein lysates were collected at $2 \mathrm{~h}$ following drug addition and subjected to immunoblotting using antibodies specific for Bcl-2 phosphorylated at thr-56 (p-Bcl-2) or total Bcl-2. The upper band 
corresponds to phospho-Bcl-2 and is indicated by the double asterik; the lower band is due to non-specific binding of antibody. Levels of phosphorylated Bcl-2 were determined by densitometry and are expressed as fold-increase in signal over solvent control $(0 \mu \mathrm{M})$. Bcl-2 protein is also shown and indicates equal protein loading for all lanes. 
A

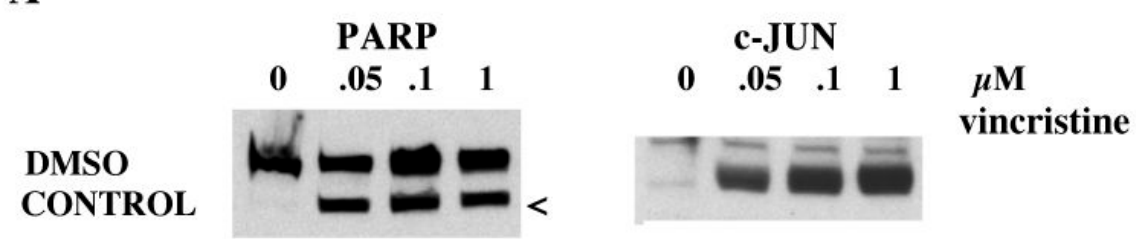

$\begin{array}{lllll}3 & 27 & 33 & 31 & \%\end{array}$

JNK INHIB. V
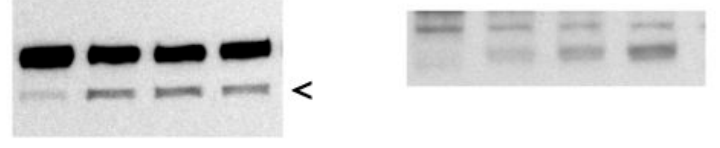

$\begin{array}{lllll}11 & 19 & 21 & 21 & \%\end{array}$

JNK INHIB. II

(NEG. CON.)
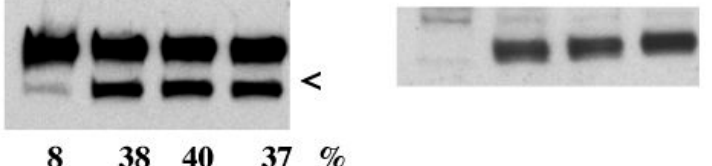

U 0126
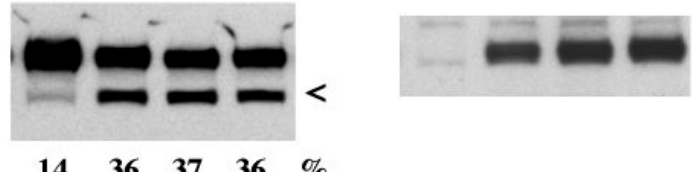

SB2
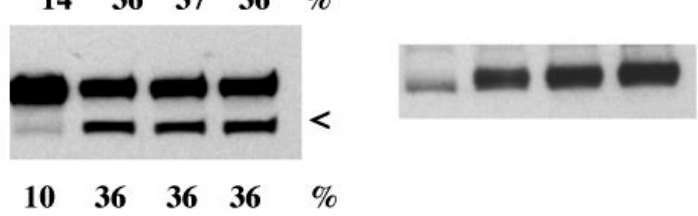

B

DMSO CONTROL

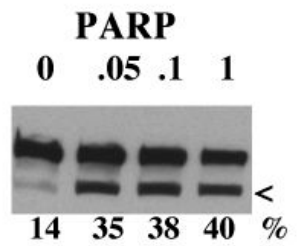

JNK INHIB. V

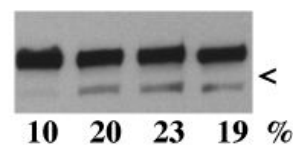

p-Bcl-2

$\begin{array}{llll}0 & .05 & .1 & 1\end{array}$

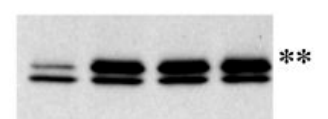

- $\quad 6.77 .27 .0$ FOLD

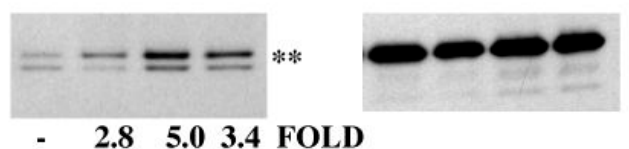

FIG 4.

Inhibition of vincristine-induced PARP cleavage and phosphorylation of Bcl-2 by two different JNK inhibitors, SP6 and JNK V. (A) Kinase inhibitors were added to cultures of EW36 B-cells $2 \mathrm{~h}$ prior to vincristine addition as follows: DMSO solvent control, JNK inhibitor V (JNK inhib.V; $10 \mu \mathrm{M}$ ); JNK inhibitor II (JNK inhib. II - negative control for SP6; $20 \mu \mathrm{M}$ ); U0126 (inhibitor of ERK; $20 \mu \mathrm{M}$ ) and SB202190 (SB2 - inhibitor of p38 kinase; 20 $\mu \mathrm{M}$ ). Protein lysates were made and immunoblots performed to detect PARP cleavage (arrow) at $24 \mathrm{~h}$ and induction of c-Jun protein at $4 \mathrm{~h}$ following vincristine addition. Percent of cleaved PARP as determined by densitometry is indicated below each lane. (B) Cultures were treated with 10 $\mu \mathrm{M}$ JNK inhibitor V (JNK inhib.V) or DMSO control $2 \mathrm{~h}$ prior to the addition of vincristine. 
Protein lysates were collected at $2 \mathrm{~h}$ following drug addition and subjected to immunoblotting using antibodies specific for Bcl-2 phosphorylated at thr-56 (p-Bcl-2) or total Bcl-2. The upper band corresponds to phospho-Bcl-2 and is indicated by the double asterik; the lower band is due to non-specific binding of antibody. Levels of phosphorylated Bcl-2 were determined by densitometry and are expressed as fold-increase in signal over solvent control $(0 \mu \mathrm{M})$. Bcl-2 protein is also shown and indicates equal protein loading for all lanes. 


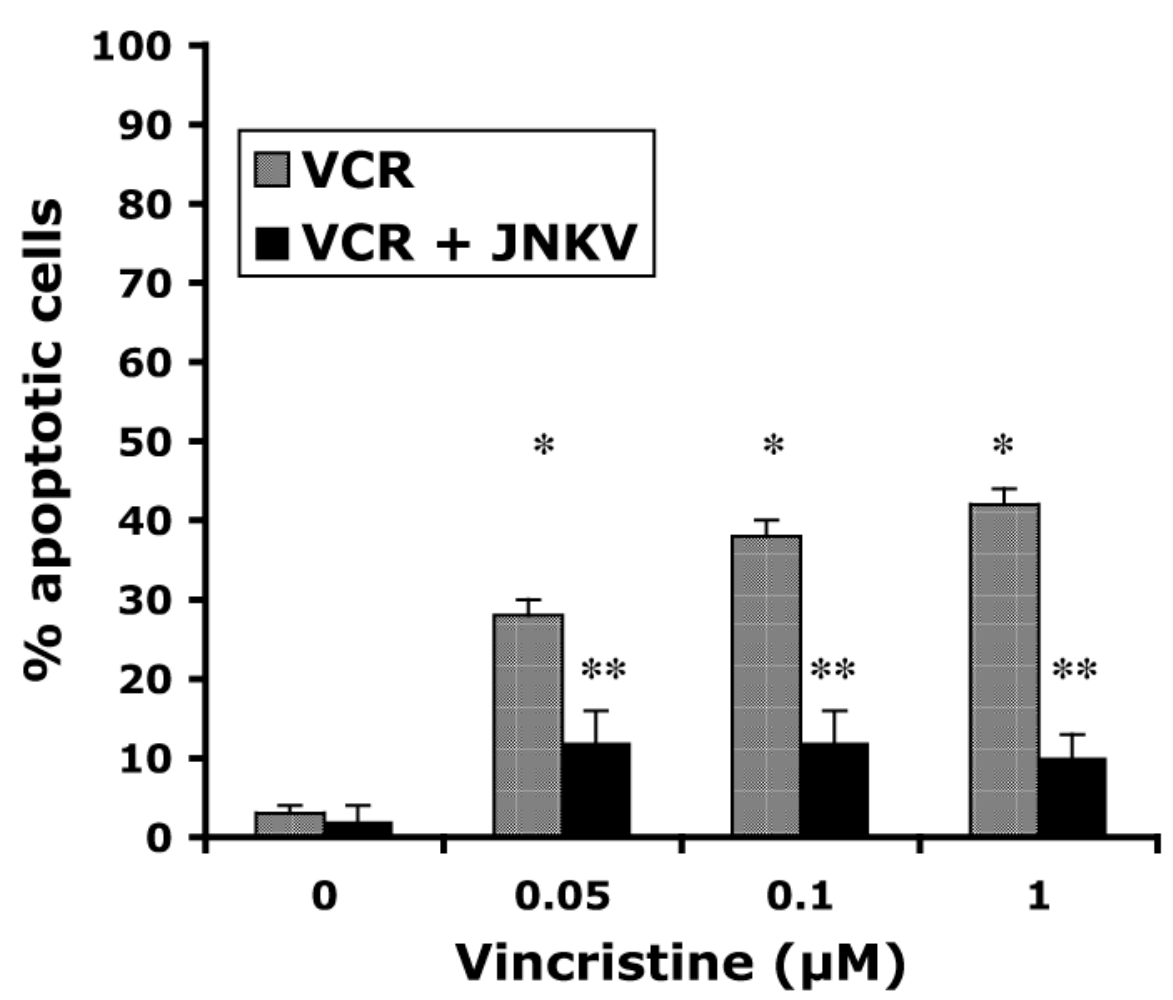

FIG 5.

Suppression of vincristine-induced apoptosis by pre-treatment with the JNK inhibitor V. Cultures of EW36 cells were pre-treated with DMSO control or $20 \mu \mathrm{M} \mathrm{JNK}$ inhibitor V for 2 $\mathrm{h}$ prior to the addition of vincristine at the indicated concentrations. Percent of apoptotic cells was determined by staining with Hoechst 33342 and propidium iodide (H/PI) followed by diagnosis of apoptosis by fluorescence microscopy as described in Materials and Methods at $24 \mathrm{~h}$. Shaded bars correspond to cultures with DMSO alone, solid bars correspond to cultures treated with JNK inhibitor V (JNK V) prior to vincristine addition. Data points are from three experiments with replicate cultures and 200 cells scored per sample. A significant induction of apoptosis was seen in cultures exposed to vincristine alone at all concentrations $\left(^{*} ; \mathrm{p}<\right.$ $0.05)$ ). Apoptosis was significantly attenuated by JNK V pre-treatment for all three concentrations of vincristine $(* ; p<0.05)$. 

A
$-\mathrm{HS}$
HSP 70
+ NL HS
$\begin{array}{llll}0 & .01 & .05 & .1\end{array}$

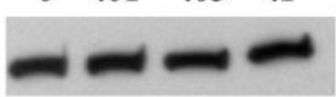
$+\mathrm{L}$ HS
$\begin{array}{lllll}0 & .01 & .05 & .1 & \mu \mathrm{M} \text { VINCRISTINE }\end{array}$

B

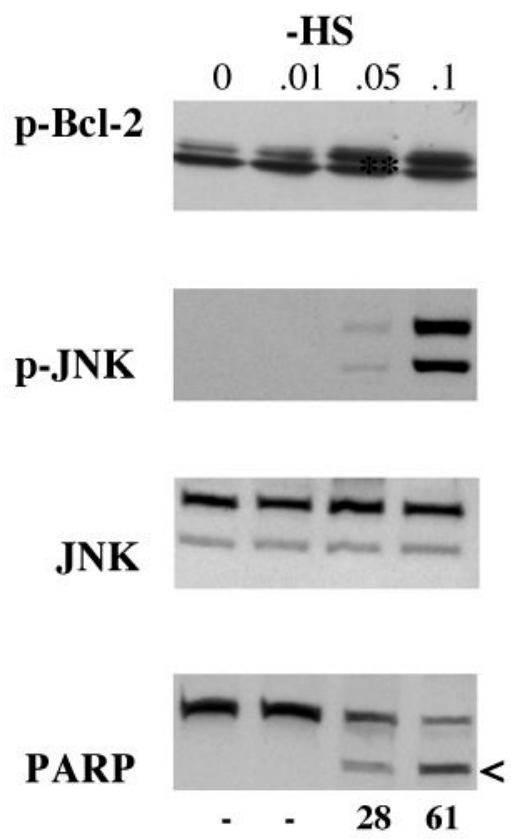

+NL HS

$\begin{array}{llllll}0 & .01 & .05 & .1 & \mu \mathrm{M} \text { VINCRISTINE }\end{array}$
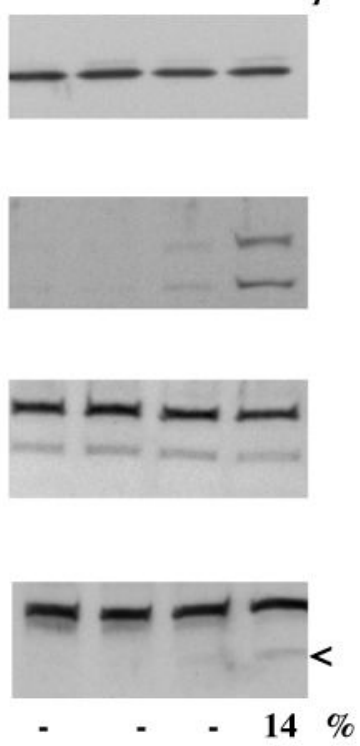

FIG 6.

Suppression of vincristine-induced JNK and Bcl-2 phosphorylation as well as PARP cleavage by pre-treatment with non-lethal heat stress. (A) Immunoblot of heat stress protein hsp 70 (HSP 70) in protein lysates from cultures exposed to the indicated concentrations of vincristine for $24 \mathrm{~h}$ without prior heat stress (-HS), or following limited, non-lethal, heat stress (+NL HS; 30 min @ $43^{\circ} \mathrm{C}$ ), or following extended, lethal heat stress, (+L HS; $1 \mathrm{~h} @ 43^{\circ} \mathrm{C}$ ). (B) Protein lysates from cultures treated with the indicated concentrations of vincristine without prior heat stress (-HS) or subjected to limited heat stress (+NL HS) were blotted for phosphorylated Bcl-2 thr 56 (p-Bcl-2, upper band, double asterik), phosphorylated JNK (p-JNK) or total JNK protein (JNK; loading control) at $2 \mathrm{~h}$ following drug addition and PARP at $24 \mathrm{~h}$ following drug addition. Percent of PARP that is cleaved (arrow) as determined by densitometry is indicated below each lane. 


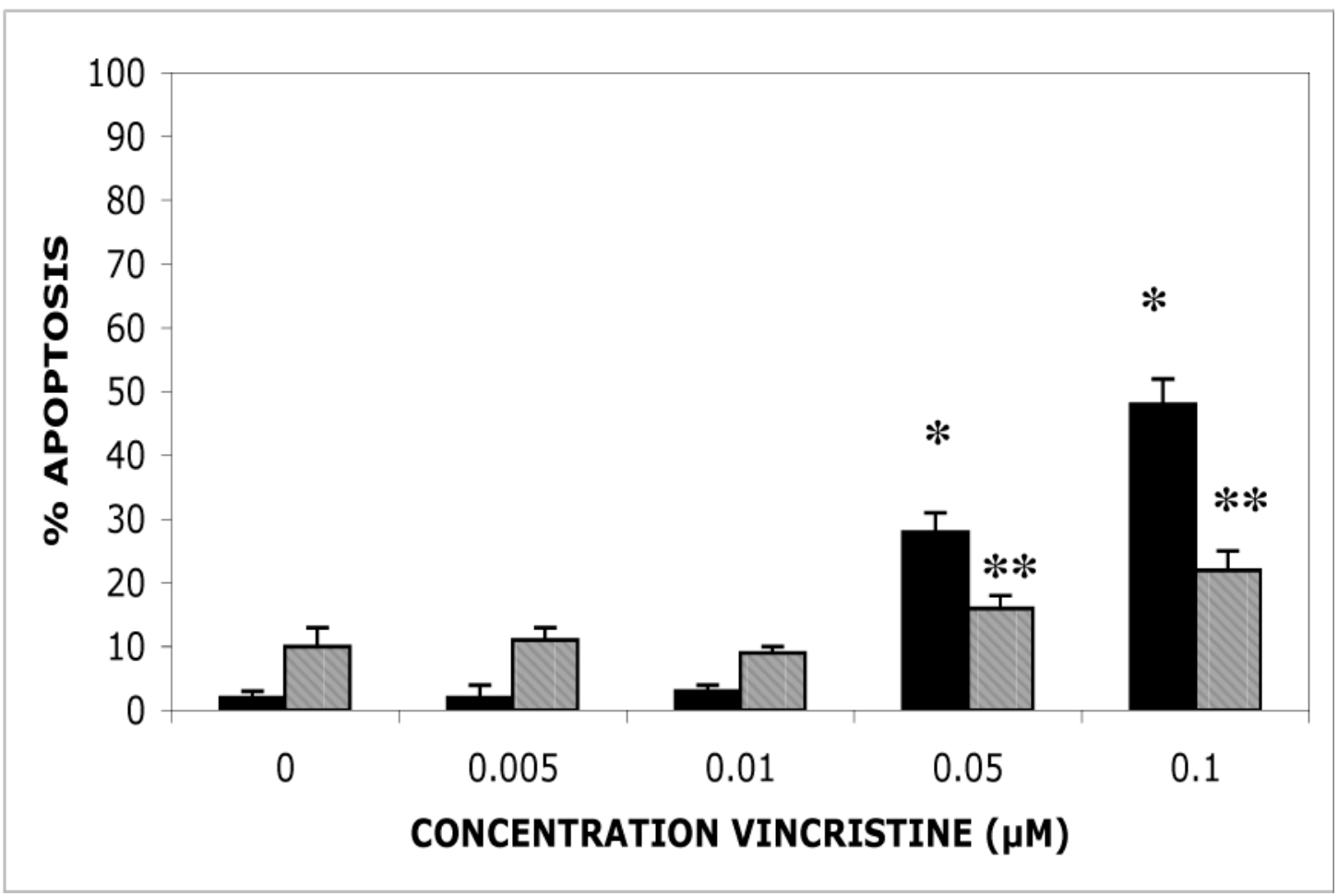

FIG 7.

Suppression of vincristine-induced apoptosis by pre-treatment with non-lethal heat stress. Percent of apoptotic cells was determined by staining with Hoechst 33342 and propidium iodide (H/PI) followed by diagnosis of apoptosis by fluorescence microscopy as described in Materials and Methods at $24 \mathrm{~h}$ following addition of the indicated concentrations of vincristine. Solid bars correspond to cultures with no prior treatment with heat stress (-HS), shaded bars correspond to cultures subjected to non-lethal heat stress (+NL HS) prior to drug addition. Data points are from three experiments with replicate cultures and 200 cells scored per sample. A significant induction of apoptosis was seen in cultures exposed to vincristine alone at 0.05 and $0.1 \mu \mathrm{M}(* ; \mathrm{p}<0.05))$. Apoptosis was significantly suppressed in cultures exposed to non-lethal heat stress prior to vincristine addition at drug concentrations of 0.05 and $0.1 \mu \mathrm{M},(* * ; \mathrm{p}<$ $0.05)$. 
A

$-H S$

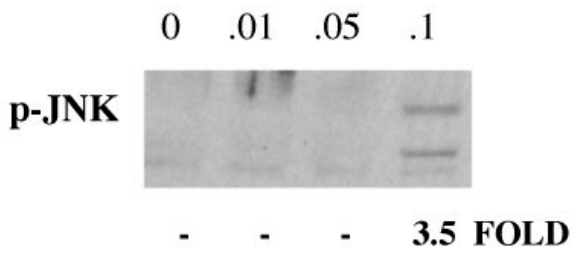

JNK

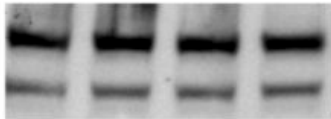

$+\mathrm{L}$ HS
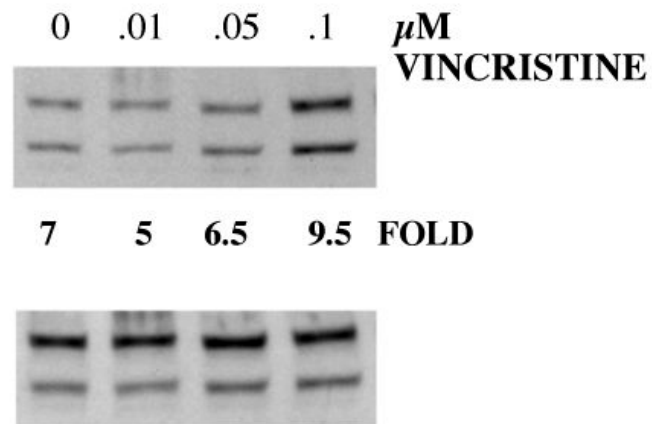

\section{B}

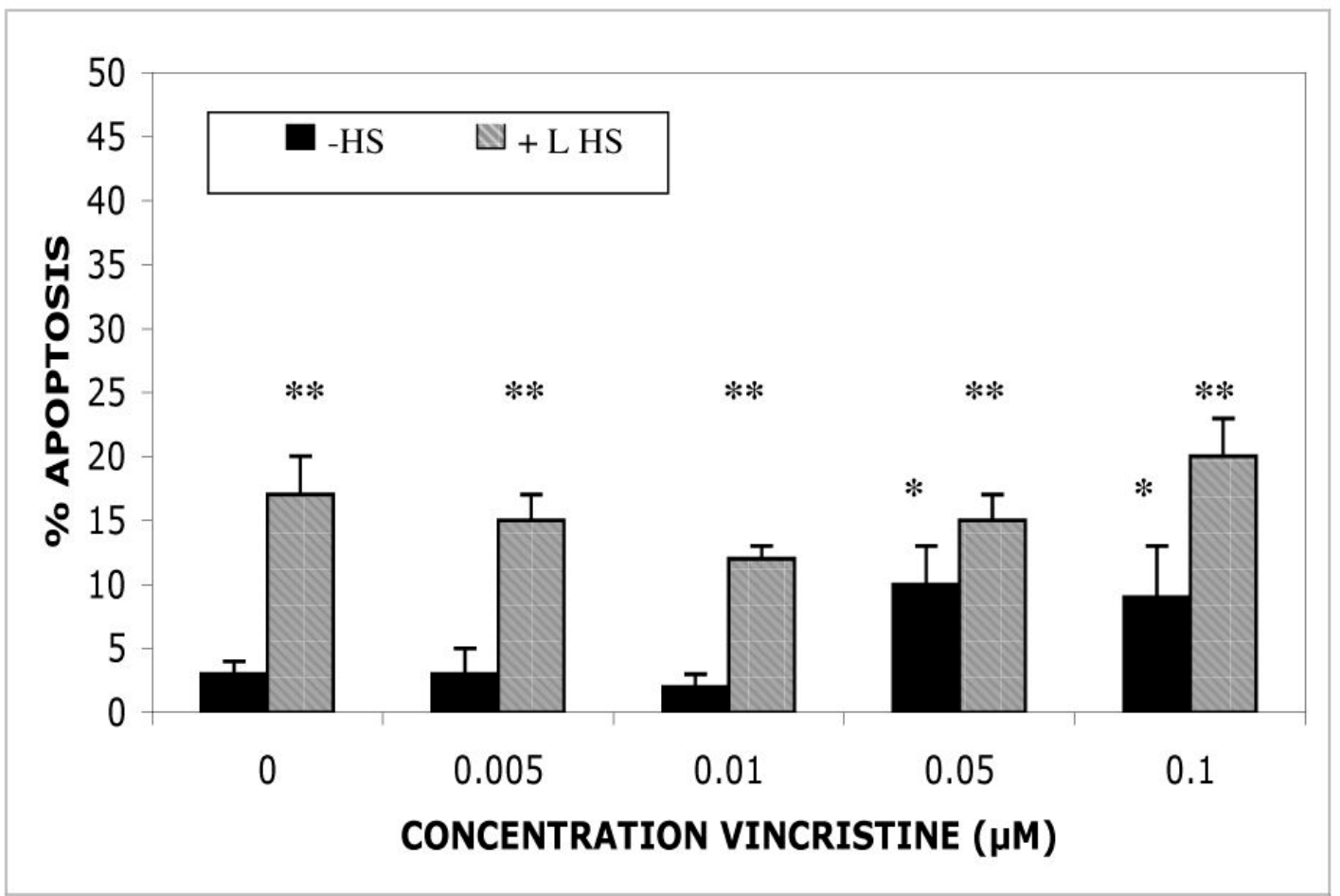

FIG 8.

Effects of lethal heat stress on vincristine-induced apoptosis. (A) Protein lysates were collected from cultures treated with vincristine at the indicated concentrations without prior heat treatment (-HS) or with prior treatment with lethal heat stress (+L HS) and blotted for phosphorylated JNK (p-JNK) or total JNK (JNK; loading control) at $2 \mathrm{~h}$ following drug addition. (B) Percent of apoptotic cells $24 \mathrm{~h}$ after drug addition at the indicated concentrations determined by staining using H/PI as described in Materials and Methods. Solid bars correspond to cultures without prior treatment with heat stress $(-\mathrm{HS})$, shaded bars correspond to cultures subjected to lethal heat stress (+L HS) prior to drug addition. Data points are from three experiments with replicate cultures and 200 cells scored per sample. Apoptosis was 
significantly increased in cultures exposed to vincristine alone starting at concentrations of $0.05 \mu \mathrm{M}(* ; \mathrm{p}<0.05)$ and in all cultures treated with lethal heat stress, with or without the addition of vincristine $(* * ; p<0.05)$. 
A

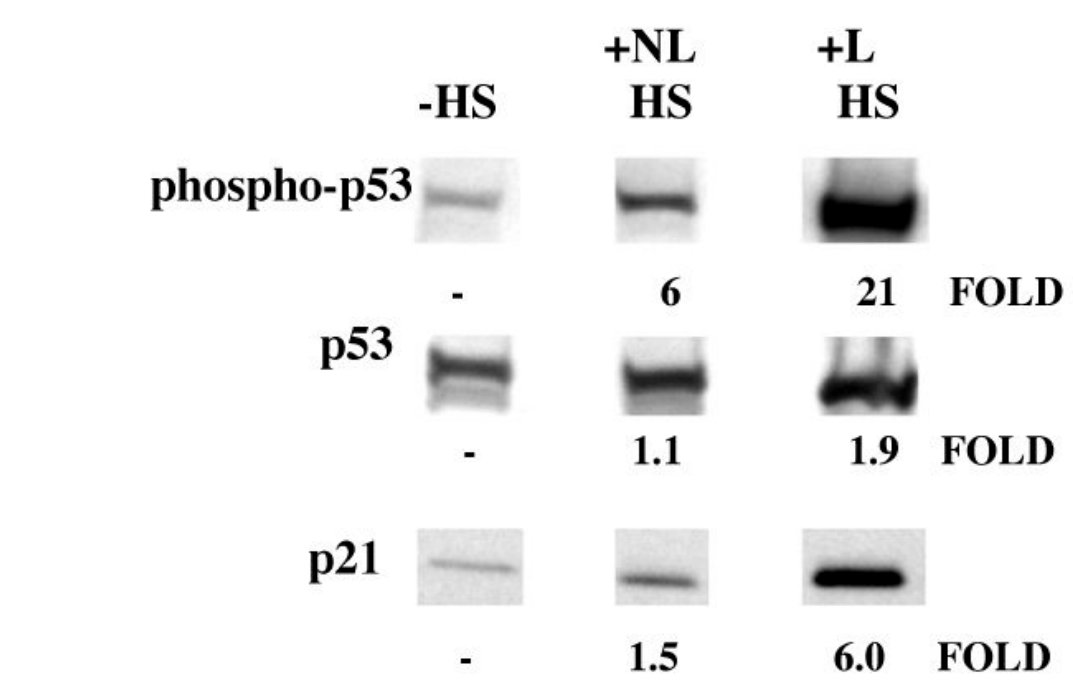

B
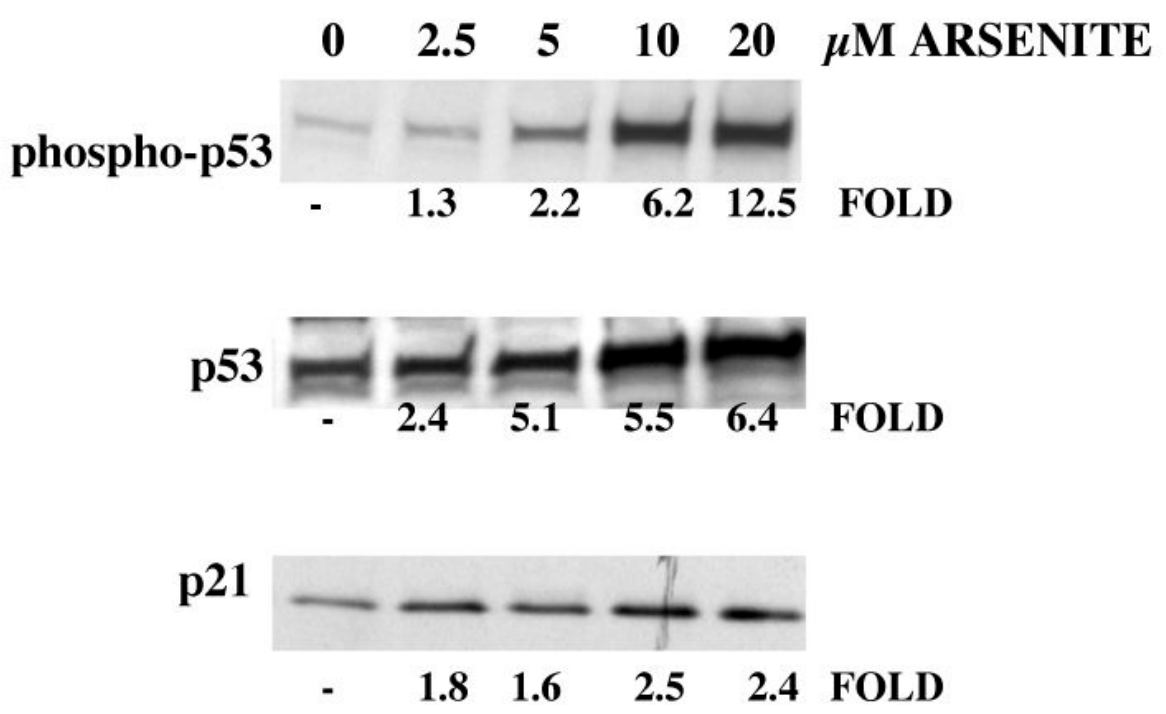

FIG 9.

Activation of the p53 pathway and induction of the p53 target gene, p21. (A) Immunoblot of cultures not subjected to heat treatment ( $-\mathrm{HS}$ ) or exposed to non-lethal heat stress (+NL HS) or lethal heat stress $(+\mathrm{L}$ HS). Protein lysates were collected at $24 \mathrm{~h}$ following treatment and blotted for phosphorylated p53 at ser-15 (phospho-p53), total p53 protein, (p53), or p21. Fold increase in signal, as determined by densitometry, is indicated below each lane. (B) Immunblot of protein lysates from cultures exposed to indicated concentrations of arsenite $24 \mathrm{~h}$ after drug addition and blotted for phospho-p53, total 53 and p21 proteins as above. 
A

vincristine

microtubule inhibition

SP6
non-
heat
$\square$
$\square$

(no apoptosis)

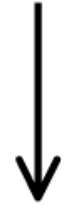

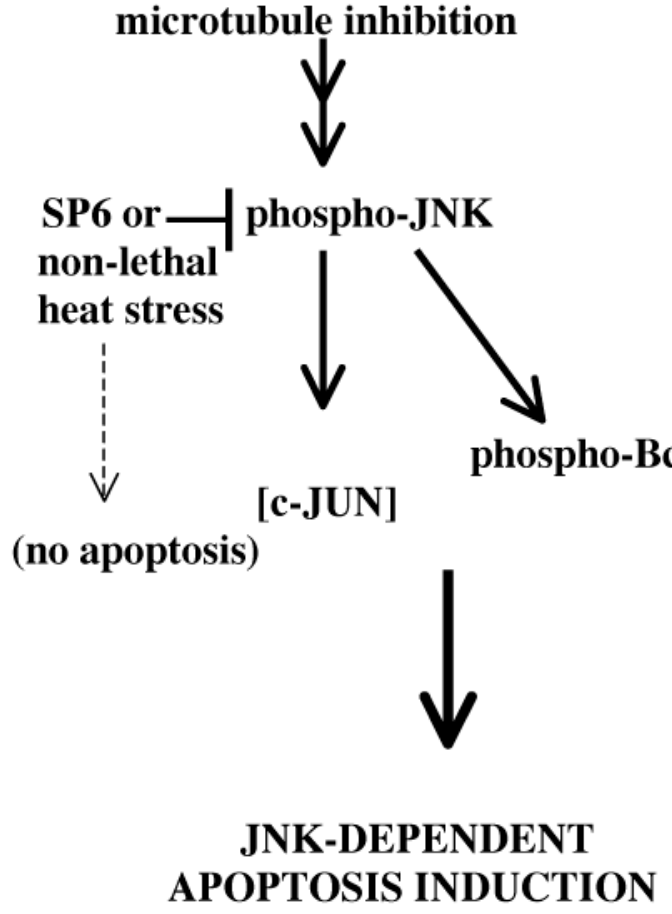

B

\section{arsenite}

(\& lethal heat stress)

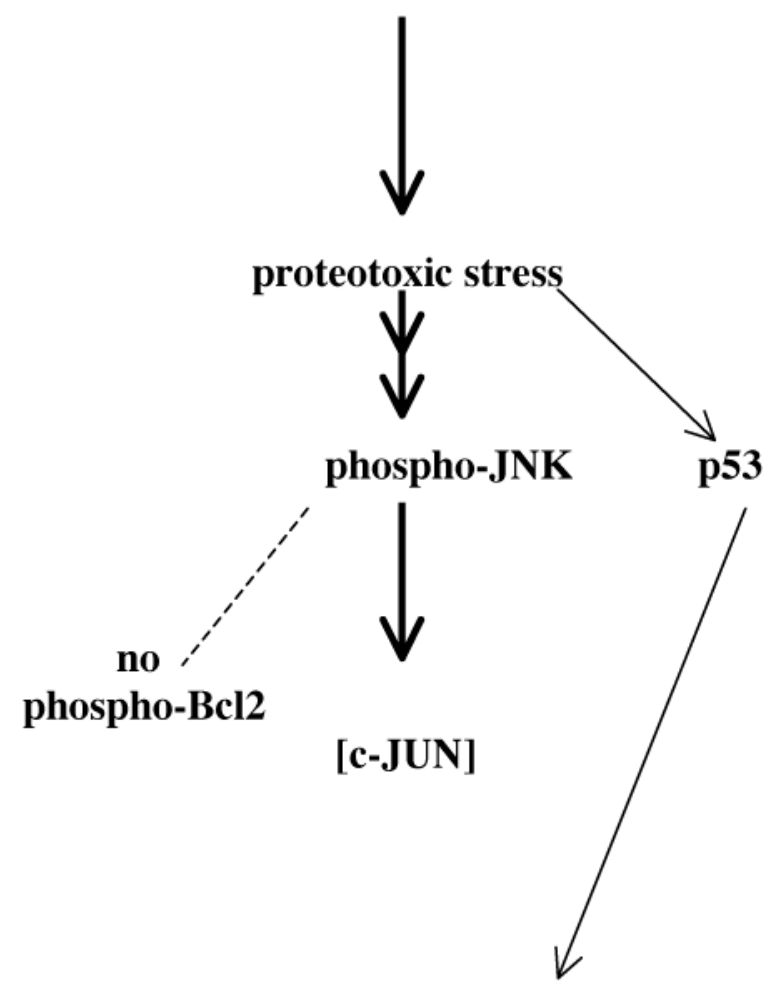

FIG 10.

Proposed pathways for JNK-dependent and JNK-independent apoptosis induction by arsenite and vincristine. (A) Vincristine induced microtubule damage leads to phosphorylation of JNK which, in turn, translocates to the nucleus and phosphorylates the transcription factor c-Jun leading to the induction of multiple nuclear substrates, including c-Jun itself. In addition, activated JNK phosphorylates the cytoplasmic substrate, Bcl-2 at thr-56 leading to its inactivation. The JNK inhibitor SP6 blocks c-Jun induction as well as Bcl-2 phosphorylation leading to an inhibition of apoptosis. Non-lethal heat stress also attenuates vincristine-induced phosphorylation of JNK and Bcl-2 thus blocking the induction of apoptosis. Whether this is due to the stabilization of microtubules by heat stress proteins or by direct effects of hypethermia on the JNK pathway is presently unknown. (B) Global proteotoxic damage induced by arsenite exposure leads to the phosphorylation of JNK that, in turn, phosphorylates the transcription factor c-Jun, leading to the induction of nuclear substrates, including c-Jun itself. However, phosphorylation of the cytoplasmic substrate Bcl-2 does not occur and 
inhibiting JNK with SP6 does not attenuate apoptosis. Lethal heat stress or arsenite (but not vincristine or non-lethal heat stress) induce a robust p53 response that is associated with apoptosis induction in this scenario. 